\title{
Studies on Storage Behavior of Primary Processed Leafy Vegetables under Different Storage Conditions
}

\author{
V.K. Garande* , P.D. Raut, U.S. Shinde, S.S. Dhumal, P.N. Sonawane and S.A. Sarvade \\ Department of Horticulture, RCSM College of Agriculture, Kolhapur-416 004, MS, India \\ *Corresponding author
}

\begin{tabular}{|l|}
\hline Ke y w or d s \\
Primary processed \\
leafy vegetables, \\
Storage conditions, \\
Shelf life, Quality \\
\hline Article Info \\
\hline $\begin{array}{l}\text { Accepted: } \\
\text { 17 May } 2019 \\
\text { Available Online: } \\
\text { 10 June 2019 }\end{array}$ \\
\hline \hline
\end{tabular}

A B S T R A C T

The present investigation was undertaken in the Post - harvest Technology Laboratory of Horticulture Section, RCSM College of Agriculture, Kolhapur during 2017-18 to study effect of storage conditions on shelf life and quality of primary processed leafy vegetables. The treatment combination comprised of three storage conditions such as room temperature (RT), zero energy cool chamber (ZECC) and refrigerated storage (RS) and five different leafy vegetables such as fenugreek, coriander, spinach, pokala and rajgira in FCRD with three replications. The freshly harvested samples of leafy vegetable were packed in polyethylene bags of 200 gauge with $2 \%$ vents and stored at different storage conditions as stated earlier. The observations on physico-chemical composition, sensorial evaluation and microbial count were recorded at regular intervals up to end of storage life of primary processed leafy vegetables. Further it was also noticed that, the increasing trend with respect to physiological loss in weight, yellowing, decay, shriveling and microbial count of primary processed leafy vegetables was noticed but the rate of increase was faster under ambient temperature as compared to zero energy cool chamber and refrigerated storage while the decreasing trend with respect to moisture, total minerals, ascorbic acid, total chlorophyll contents and sensorial qualities, but the rate of decrease was slow under refrigerated storage conditions as compared to zero energy cool chamber and room temperature. It was also found, that the moisture and mineral contents of primary processed leafy vegetables were ranged from $90 \%\left(\mathrm{~V}_{5} \mathrm{~S}_{3}\right)$ to $80.04 \%\left(\mathrm{~V}_{1} \mathrm{~S}_{1}\right)$ and $25.23 \%$ $\left(\mathrm{V}_{1} \mathrm{~S}_{3}\right)$ to $12.23 \%\left(\mathrm{~V}_{5} \mathrm{~S}_{1}\right)$, respectively at the end of storage life. The highest ascorbic acid retention was noticed in $\mathrm{V}_{1} \mathrm{~S}_{3}(88.86 \%)$ whereas the lowest was noticed in $\mathrm{V}_{3} \mathrm{~S}_{1}(21.03 \%)$ at the end of storage life. The total chlorophyll content was found to be ranged in between $30.67 \mathrm{mg} / 100 \mathrm{~g}\left(\mathrm{~V}_{2} \mathrm{~S}_{1}\right)$ and $82.82 \mathrm{mg} / 100 \mathrm{~g}\left(\mathrm{~V}_{4} \mathrm{~S}_{3}\right)$ at the end of storage life of primary processed leafy vegetables. The shelf life of primary processed fenugreek, coriander, spinach, pokala and rajgira could be extended to 2, 3 and 8 days, 2, 3 and 6 days, 2, 4 and 8 days, 2, 4 and 6 days and 2, 4 and 8 days at room temperature, zero energy cool chamber and refrigerated storage, respectively on the basis of physiological loss in weight, sensorial qualities and microbial count. 


\section{Introduction}

India is the second largest producer of vegetables in the world and accounts for about 15 percent of the world's vegetable production. India's flora comprises of 6000 species of plants and used for consumption, one third of which are green leafy vegetables. Green Leafy Vegetables (GLV) having much importance from the nutritional point of view (Narang et al., 2016). The majority of people in India are economically poor and thus food choices for balanced diet are further restricted by poverty and insufficient supply of nutritious food. Green leafy vegetables are particularly rich in carotenoids (vitamin A) as well as protein, calcium, vitamin $\mathrm{C}$, riboflavin, iron, magnesium, phosphorus, potassium, fiber and vitamins like folic acid, $\mathrm{K}, \mathrm{E}$ and other mineral (Gibson, 1994) and being rich in these nutrients, green leafy vegetables help to combat micro-nutrient deficiencies (Borah et al., 2008).The high concentration in certain bioactive phytochemical normally present in vegetables is the reason for their recommendations, being the high intake of vegetables correlated to lower incidence of chronic diseases (Devdas et al., 1980 and Prakash and Pal,1991) .

The fruits and vegetables continue to respire, transpire and ripen even after harvesting; therefore, they suffer losses in their quality and quantity between harvest and consumption. However, these losses can be avoided to some extent and the shelf -life can be extended by using appropriate production practices such as pre- cooling, packaging, storage and transportation. The post - harvest practices, refrigerated storage and packaging of vegetables can contribute in an integrated manner to reduce the losses. Because of the changes in consumer lifestyles, there is an increased demand of fresh-cut primarily processed food items, which are nutritious, functional, safe, attractive, and ready-to-eat.
Minimally processed vegetables become a convenient answer to those who want to include more fresh vegetables in the daily diet (Kaur and Kapoor, 2000).

The different leafy vegetables such as fenugreek (Trigonella foenum- graceum L.), coriander (Coriandrum sativum L.), spinach (Spinacia oleracea L.), pokala (Amarathus blitum) and rajgira (Amarathus paniculatus L.) contain higher amount of vitamins, minerals and other nutritional components which helps in maintain the proper health. Fenugreek plays an important role in medicines as fenugreek having vital role in promoting lactation, reduces menstrual discomfort and minimizes symptoms of menopause while coriander is helpful in reducing skin inflammation and cholesterol, regulates blood pressure and preventing ulcers (Gopalan et al., 1982).

The minimal processing plays an important role in reducing the problems of garbage disposal in the metropolitan cities (Gomez et al., 2003). Work done in minimal processing of different green leafy vegetables showed that, shelf life of spinach can be extended from 3 days to 14 days by using LDPE bags at cold storage (Kakade et al., 2015). Reddy et al. (2013) in rajgira who recorded the shelf life of 6 days under refrigerated storage while Kulkarni (2015) recorded the shelf life of 10 days for fenugreek in refrigerated storage with better retention of physico-chemical properties.

Hence, there is great scope for enhancing the shelf life of different green leafy vegetables along with better retention of their nutritive value and provide ready - to - cook leafy vegetables in consumer hands and hence the vegetables such as fenugreek, coriander, spinach, pokala and rajgira were selected for studying their storage behavior under different storage conditions. Keeping all these 
points in mind, the present research work was carried out to study the effect of storage conditions on shelf life and quality of primary processed leafy vegetables.

\section{Materials and Methods}

The healthy, fresh and photo-synthetically active leaves of optimal maturity of leafy vegetables viz. fenugreek, coriander, spinach, pokala and rajgira were collected from Instructional - cum- Research farm of Horticulture Section, RCSM College of Agriculture, Kolhapur and from local market of Kolhapur also. The bay as well as working and drying area of laboratory and all other instruments and equipment were sanitized with 100 ppm chlorine solution and air dried. The selected vegetables were sorted for integrity, color and size uniformity and lack of defects. Only photosynthetic leaves (green leaves) with tender stem were included in the samples. Selected leaves along with tender stem parts of leafy vegetables were washed in running tap water for 4 minutes at room temperature $\left(20^{\circ} \mathrm{C}\right)$ in a ratio of one part of sorted leafy vegetable for 10 parts of water. The excess water was drained by using sterilized stainless steel sieves. The prepared vegetables were spread on tables and air dried. Consumer polyethylene food grade plastic bags of $25 \times 20 \mathrm{~cm}$ size having 200 gauge with $2 \%$ vent were used for packaging. Processed vegetables weighing $100 \mathrm{~g}$ were filled in each polyethylene bags and bags were sealed by using hand operated pouch sealing machine. The well packed primary processed vegetables were stored at three different storage conditions i.e. room temperature (RT), zero energy cool chamber (ZECC) and refrigerated storage (RS, $\left.5 \pm 1^{\circ} \mathrm{C}\right)$.

\section{Physico-chemical analysis of primary processed leafy vegetables}

Approximately 5 to 10 leaves of vegetable selected for primary processing were taken and their outer boarder was drawn on graph paper. Total area covered with leaf was measured and recorded in $\mathrm{cm}^{2}$. The percent moisture was determined by drying known weight of sample into hot air oven at $60^{\circ} \mathrm{C}$ for 24 hours up to a constant known weight (A.O.A.C., 2010). The Total mineral content was estimated in terms of per cent and the total chlorophyll content were estimated as per the standard procedure given by Ranganna (2005) in terms of $\mathrm{mg} / 100 \mathrm{~g}$. Ascorbic acid was estimated as per the modified titration procedure of A.O.A.C (2010) and measured in terms of ascorbic acid content in terms of $\mathrm{mg}$ per $100 \mathrm{~g}$ of leaves.

\section{Sensorial evaluation}

Overall acceptability score for primary processed leafy vegetables was determined on the basis of colour, appearance, texture, aroma parameters of samples by a panel of evaluators based on rating with 9-point Hedonic scale given by Amerine et al. (1965). Overall rating was calculated and a score of 5.50 and above was considered as acceptable. Samples which recorded the score less than 5.50 were terminated.

\section{Total microbial count (cf/g)}

Total microbial count was calculated as per the standard procedure given by the Ranganna (2005) at initial and at termination of the treatment.

\section{Statistical analysis}

The data was reported as an average value of replicates with standard deviation. Analysis of variance (ANOVA) was performed using IBM SPSS Statistics 22 (Windows 8.1, Statistical analysis). The level of significance for all the tests was $\alpha=0.05$ (Panse and Sukhatme, 1985). 


\section{Results and Discussion}

\section{Analysis of selected vegetables before primary processing}

The data depicted in Table 1 revealed that among all the vegetables, highest weight of inedible portion was observed in coriander $(655.80 \mathrm{~g})$ followed by pokala $(609.59 \mathrm{~g})$ and fenugreek $(600.25 \mathrm{~g})$ at the same time spinach showed the least weight of inedible portion $(351.50 \mathrm{~g})$ followed by rajgira $(408.50 \mathrm{~g})$. It was also noticed that, the highest edible portion was noticed in spinach $(648.50 \mathrm{~g})$ followed by rajgira $(591.50 \mathrm{~g})$. The remaining vegetable viz. fenugreek, and pokala had weight of edible portion was $399.75 \mathrm{~g}$ and $390.41 \mathrm{~g}$, respectively. The least weight of edible portion was found in coriander $(344.20$ g) as it had very small leaf area and its leaves are mostly taken as edible portion. As spinach with short tender leaves are considered edible for consumption as well as leaves of spinach having large leaf surface area and hence spinach recorded highest per cent edible portion (64.80) followed by rajgira (59.15) while other vegetables viz. fenugreek, coriander and pokala recorded comparatively less percentage of edible portion such as 39.97, 34.40 and 39.04, respectively as these vegetables had comparatively smaller leaf area than spinach and rajgira. The results of present findings are in accordance with the findings of Gomez et al., (2003) who recorded $45-50 \%$ inedible portion in fenugreek

\section{Physico-chemical Composition of Primary Processed Leafy Vegetables}

\section{Physical constituents / traits}

\section{Physiological loss in weight $(\%)$}

The data presented in Table 2 clearly indicated that, the physiological loss in weight of primary processed leafy vegetables was found to be increased with advancement of storage period. On $2^{\text {nd }}$ day of storage, $V_{1}$ recorded highest physiological loss in weight $(7.54 \%)$ while least PLW was recorded by $\mathrm{V}_{5}$ $(5.03 \%)$. The vegetable $\mathrm{V}_{2}$ recorded highest PLW $(9.73 \%)$ and least PLW was noticed in $\mathrm{V}_{5}(7.33 \%)$ at the end of $6^{\text {th }}$ day of storage. On $8^{\text {th }}$ day of storage, highest PLW was observed in $\mathrm{V}_{1}(11.21 \%)$ and lowest PLW was recorded by $\mathrm{V}_{5}(8.25 \%)$.

Individual effect of different storage conditions on physiological loss in weight of different primary processed leafy vegetables was found to be significant and presented in Table 2. The data revealed that on $2^{\text {nd }}$ day of storage, $\mathrm{S}_{1}$ recorded highest PLW $(10.85 \%)$ and lowest PLW was recorded by $\mathrm{S}_{3}(3.12$ $\%)$. At the end of $6^{\text {th }}$ day of storage, $\mathrm{S}_{3}$ recorded physiological loss in weight of 8.54 $\%$ and on $8^{\text {th }}$ day it was $(9.64 \%)$. The physiological loss in weight was found to be increased gradually throughout the storage irrespective of storage conditions. Rayaguru et al. (2010) reported that PLW at RT and ZECC was more might be due to fluctuation in outside temperature which adversely affected the relative humidity and increases PLW. The results of present findings are in accordance with the findings of Ambuko et al. (2017) who stated that the rate of PLW was affected by temperature and relative humidity which affects the VPD (Vapour Pressure Difference) between products and its environment and it can be controlled by reducing temperature and increasing relative humidity which might be reason for longest shelf life of vegetables at $\mathrm{S}_{3}$ i.e. refrigerated storage.

The interaction effect of different treatment combinations of vegetable types and different storage conditions on physiological loss in weight was found to be increased with increase in storage period as presented in 
Table 2. At the end of $2^{\text {nd }}$ day of storage, treatment combination of $\mathrm{V}_{1} \mathrm{~S}_{1}$ recorded highest physiological loss in weight $(13.11 \%)$ closely followed by $\mathrm{V}_{4} \mathrm{~S}_{1}(12.45 \%)$ whereas lowest physiological loss in weight was recorded by $\mathrm{V}_{5} \mathrm{~S}_{3}(2.76 \%)$ which was closely followed by $\mathrm{V}_{4} \mathrm{~S}_{3}(2.78 \%)$. On $6^{\text {th }}$ day of storage, $\mathrm{V}_{2} \mathrm{~S}_{3}$ recorded highest physiological loss in weight $(9.73 \%)$ closely followed by $\mathrm{V}_{4} \mathrm{~S}_{3}(9.71 \%)$. On $8^{\text {th }}$ day of storage, $\mathrm{V}_{1} \mathrm{~S}_{3}$ recorded highest physiological loss in weight (11.21\%) followed by $\mathrm{V}_{3} \mathrm{~S}_{3}(9.47 \%)$ whereas the least PLW was recorded by $\mathrm{V}_{5} \mathrm{~S}_{3}(8.25 \%)$.

The highest PLW was recorded in the primary processed vegetables stored at ambient storage than ZECC and RS. The similar results were also reported by Chauhan (1981) in vegetables, Waskar et al. (1999) in bottle gourd fruits and Negi and Roy (2004) leafy vegetables. The least PLW was recorded in refrigerated storage as it had highest humidity and lower temperature. Weight loss is a very important factor as it is associated with economic issues and generally weight loss more than 5-10\% reduces the market value of vegetables (Brown and Bourne, 2002). Water loss in vegetables is determined by many factors, the most important of which is the resistance exerted by the outer periderm or cuticle movement of water vapour due to transpiration as reported by Ben-Yehoshua (1987). The temperature and relative humidity must be controlled for preventing the moisture loss of vegetables as reported by Thompson (2004). The present findings are in comparable with Kulkarni (2015) in fenugreek and spinach, Sharangi et al., (2015) in coriander, Ambuko et al. (2017) in leafy amaranthus and Indore et al. (2017) in okra, and under different storage conditions.

\section{Yellowing (\%)}

Yellowing percentage calculated by recording the observations at every alternate day from the zero day of storage till the end of storage life. Slightly yellowed leaves were sorted from the samples and yellowing percentage was calculated. The data depicted in Table 2 emphasized on the findings occurred while recording the yellowing of different leafy vegetables used for investigation.

It is clearly seen from the data presented in Table 2 that individual types of vegetable showed significant effect on yellowing under different storage conditions. On $2^{\text {nd }}$ day of storage, $\mathrm{V}_{1}$ recorded highest yellowing (4.72 $\%)$ followed by $\mathrm{V}_{2}(2.97 \%)$ and lowest yellowing was recorded by $\mathrm{V}_{4}(1.43 \%)$. At the end of $6^{\text {th }}$ day of storage, $V_{1}$ marked the yellowing of $4.89 \%$ which was highest among all vegetables while lowest yellowing was recorded by $\mathrm{V}_{4}(1.64 \%)$. On the end of $8^{\text {th }}$ day of storage, $\mathrm{V}_{1}$ recorded the highest yellowing $(5.07 \%)$ and least yellowing was depicted in $\mathrm{V}_{5}(2.03 \%)$. Further, it was noticed that the yellowing percentage was increased throughout the storage period irrespective of storage conditions.

The data presented in Table 2 gives an account of individual effect of different storage conditions on yellowing of different primary processed leafy vegetables was found to be significant. The storage condition $\mathrm{S}_{1}$ recorded highest yellowing of $4.24 \%$ and the lowest yellowing was recorded by $\mathrm{S}_{3}(0.41 \%)$ at the end of $2^{\text {nd }}$ day of storage. On $8^{\text {th }}$ day of storage, $\mathrm{S}_{3}$ recorded the least yellowing (3.40 $\%)$ at refrigerated conditions thereafter samples were discarded. It was also revealed that, yellowing was increased as storage period advanced throughout the storage period. Faster rate of yellowing was occurred at room temperature followed by ZECC and refrigerated storage. The lowest rate of yellowing was recorded at refrigerated storage it might be due to prevalence high humidity and lower temperature as recorded by Hou $e t$ al. (2003) in spinach and findings of present investigation are in accordance with results reported by Reddy et al. (2013) in rajgira 
(Fig. 1). With a brief glance on Table 2 it can be vividly perceived that, interaction effect of types of vegetable and different storage conditions on yellowing of primary processed leafy vegetables was found to be significant in all the treatment combinations. On $2^{\text {nd }}$ day of storage, $\mathrm{V}_{1} \mathrm{~S}_{1}$ recorded highest yellowing $(7.14 \%)$ followed by $\mathrm{V}_{1} \mathrm{~S}_{2}(6.03 \%)$ and lowest yellowing was recorded by $\mathrm{V}_{2} \mathrm{~S}_{3}(0.25 \%)$ while no yellowing was recorded by $\mathrm{V}_{5} \mathrm{~S}_{3}$ at the end of $2^{\text {nd }}$ day of storage. At the end of $6^{\text {th }}$ of storage, highest yellowing was recorded by $\mathrm{V}_{1} \mathrm{~S}_{3}(4.89 \%)$ and lowest was recorded by $\mathrm{V}_{4} \mathrm{~S}_{3}(1.64 \%)$. At the end of $8^{\text {th }}$ day of storage, highest yellowing was recorded by $\mathrm{V}_{1} \mathrm{~S}_{3}(5.07 \%)$ and lowest yellowing was recorded by $\mathrm{V}_{5} \mathrm{~S}_{3}(2.03 \%)$, followed by $\mathrm{V}_{3} \mathrm{~S}_{3}(3.11 \%)$. As yellowing is an inevitable symptom of senescence in vegetables and hence, it is most important factor influenced the shelf- life as well as overall acceptability of vegetables. The trend of increase in yellowing of all the samples of vegetable irrespective of storage conditions was noticed. The results of present findings are in parallel with the results recorded by Reddy (2013) in rajgira.

\section{Decay (\%)}

Data presented in Table 3 gives an account of decay of primary processed leafy vegetables was differed significantly. It was found that, the increasing trend in decay was observed in primary processed leafy vegetables under various storage conditions throughout the storage period irrespective of vegetables. On $2^{\text {nd }}$ day of storage, $\mathrm{V}_{1}$ recorded highest decay of $2.62 \%$ and lowest was noticed in $\mathrm{V}_{4}(1.84$ $\%)$. At the end of $6^{\text {th }}$ day of storage, $\mathrm{V}_{1}$ recorded highest decay of $2.93 \%$ whereas lowest decay was observed in $\mathrm{V}_{4}(2.36 \%)$. On $8^{\text {th }}$ day of storage, $\mathrm{V}_{1}$ recorded highest decay $(3.43 \%)$ and closely followed by $\mathrm{V}_{3}$ $(3.03 \%)$ and lowest decay was noted in $\mathrm{V}_{5}$ $(2.89 \%)$ and samples were discarded due to market unacceptability.
With a short glance in Table 3 it is revealed that individual effect of different storage conditions on decay of vegetables was found to be significant. $S_{1}$ had highest temperature and lowest humidity which leads to faster rate of respiration among the vegetables and resulted into more decay and in the short storage life. Comparatively decay was lower in $S_{2}$ than $S_{1}$, as it had lower temperature and higher humidity than RT i.e. $\mathrm{S}_{1}$ recorded the decay of $3.82 \%$ on $2^{\text {nd }}$ day of storage. On $6^{\text {th }}$ day and $8^{\text {th }}$ day of storage, $\mathrm{S}_{3}$ recorded decay of 2.70 and $3.12 \%$, respectively. Among the storage conditions, $\mathrm{S}_{3}$ was depicted lowest decay as it had highest humidity and no fluctuation of temperature which restrict the respiration rate and hence lower decay in vegetables at the end of storage life.

It was also noticed that, the interaction effect of different storage conditions and types of vegetable on decay in all treatments was found to be significant. On $2^{\text {nd }}$ day of storage, of $\mathrm{V}_{1} \mathrm{~S}_{1}$ recorded highest decay $(5.20 \%)$ followed by $\mathrm{V}_{3} \mathrm{~S}_{1}(4.01 \%)$ whereas lowest decay was recorded by treatment $\mathrm{V}_{4} \mathrm{~S}_{3}(0.65$ $\%)$ followed by $\mathrm{V}_{5} \mathrm{~S}_{3}(0.90 \%)$. At the end of $6^{\text {th }}$ day of storage, $\mathrm{V}_{3} \mathrm{~S}_{3}$ recorded highest decay $(2.93 \%)$ followed by $\mathrm{V}_{2} \mathrm{~S}_{3}(2.83 \%)$ and lowest decay was recorded by $\mathrm{V}_{4} \mathrm{~S}_{3}(2.36$ $\%$ ) followed by $\mathrm{V}_{5} \mathrm{~S}_{3}(2.57 \%)$. On $8^{\text {th }}$ day of storage, of $\mathrm{V}_{1} \mathrm{~S}_{3}$ recorded highest decay $(3.43 \%)$ whereas lowest decay was recorded by $\mathrm{V}_{5} \mathrm{~S}_{3}(2.89 \%)$. Among all treatment combinations, $\mathrm{V}_{5} \mathrm{~S}_{3}$ recorded the least decay and responded better to have more shelf life. The increasing trend with respect to decay of primary processed leafy vegetables was noticed during storage irrespective of types of vegetable and storage conditions. The low levels of oxygen favours fermentation processes which might cause the formation of the acetaldehyde and off flavour compounds which may cause decay as reported by Kaur and Kapoor (2000) in minimally processed fruits and vegetables. Quadri et al. (2015) 
observed that, leafy vegetables have an array of advantages but are highly perishable in nature which leads them to higher decay. The results of present findings are in accordance with the results reported by Kulkarni (2015) in spinach and fenugreek and Sharangi et al. (2015) in coriander.

\section{Shriveling (\%)}

The data shown in Table 3 gives an account of shriveling (\%) of different primary processed leafy vegetables under different storage conditions was found to be influenced significantly. The highest shriveling percentage was recorded by $\mathrm{V}_{2}(8.19 \%)$ closely followed by $\mathrm{V}_{5}(7.98 \%)$ whereas lowest shriveling was noticed in $\mathrm{V}_{3}(6.52 \%)$ and $V_{1}(6.97 \%)$ at the end of $2^{\text {nd }}$ day of storage. On $6^{\text {th }}$ day of storage, $\mathrm{V}_{2}$ recorded the highest shriveling $(10.12 \%)$ and lowest was observed in $\mathrm{V}_{1}(8.15 \%)$. On $8^{\text {th }}$ day of storage, $\mathrm{V}_{1}$ recorded highest shriveling $(11.13 \%)$ and lowest was recorded by $\mathrm{V}_{5}(9.86 \%)$. The shriveling percentage of primary processed leafy vegetables showed the increasing trend in all the vegetables under study.

Individual effect of different storage conditions on shriveling was found to be significant as emphasized in Table 3 . The data revealed that, $S_{1}$ recorded the highest percentage of shriveling due to high temperature while $S_{2}$ recorded comparatively less shriveling than $S_{1}$ and higher than $S_{3}$. The storage conditions $S_{3}$ had highest humidity and lowest temperature than other storage conditions hence recorded lowest shriveling. On $2^{\text {nd }}$ day of storage, the shriveling percentage was found to be maximum in $S_{1}$ (12.09\%) followed by $S_{2}(7.03 \%)$ and $S_{3}$ $(3.06 \%)$. The samples stored at $\mathrm{S}_{3}$ condition recorded the shriveling of $11.09 \%$ at the end $8^{\text {th }}$ day of storage. Rate of shriveling was faster at room temperature $\left(S_{1}\right)$ followed by ZECC $\left(\mathrm{S}_{2}\right)$ and refrigerated storage $\left(\mathrm{S}_{2}\right)$. The shriveling percentage showed the increasing trend during the storage irrespective of storage conditions. Similar results were also recorded by Garande (1992) in jamun fruits.

The data presented in Table 3 gives a clear representation of interactions of different storage conditions and vegetable types showed increasing trend with respect to shriveling in all vegetables under study. On $2^{\text {nd }}$ day of storage, $\mathrm{V}_{5} \mathrm{~S}_{1}$ recorded highest shriveling $(14.11 \%)$ followed by $\mathrm{V}_{1} \mathrm{~S}_{1}(12.86$ $\%)$ whereas lowest shriveling was recorded by $\mathrm{V}_{5} \mathrm{~S}_{3}(1.96 \%)$ followed by $\mathrm{V}_{4} \mathrm{~S}_{3}(2.16 \%)$. On $6^{\text {th }}$ day of storage, $\mathrm{V}_{2} \mathrm{~S}_{3}$ recorded highest shriveling $(10.12 \%)$ followed by $\mathrm{V}_{4} \mathrm{~S}_{3}(10.02$ $\%)$ and lowest was recorded by $\mathrm{V}_{1} \mathrm{~S}_{3}(8.15$ $\%)$. On $8^{\text {th }}$ day of storage, $\mathrm{V}_{1} \mathrm{~S}_{3}$ recorded highest shriveling of $11.13 \%$ and lowest was recorded by $\mathrm{V}_{5} \mathrm{~S}_{3}(9.86 \%)$. The shriveling of primary processed leafy vegetables was found to be increased during the storage period irrespective of types of vegetable and storage conditions. The results of present investigation are in close conformity with the results of earlier research workers such as Garande (1992) in jamun fruits and Sharangi et al. (2015) in coriander.

\section{Moisture (\%)}

The data depicted in Table 4 clearly indicated that the moisture content of primary processed vegetables exhibited the decreasing trend throughout the storage period irrespective of types of vegetable and storage conditions.

The moisture content of primary processed vegetable was found to be differed significantly among the different vegetables. Initially, highest moisture content was recorded in $\mathrm{V}_{3}(94.00 \%)$ followed by $\mathrm{V}_{2}$ $(92.24 \%)$ whereas the lowest was noticed in $\mathrm{V}_{5}(87.55 \%)$. It was clearly seen that the vegetables which had thick and fleshy cuticle 
were contained highest moisture percentage and the vegetables which had thin cuticle were recorded minimum moisture percentage. At the end of shelf life moisture content was found to be highest in $\mathrm{V}_{3}(85.65 \%)$ whereas the lowest moisture content was noticed in $\mathrm{V}_{5}$ $(82.25 \%)$. It was also seen that the least moisture loss was recorded in $\mathrm{V}_{5}(5.30 \%)$ whereas the highest moisture loss was observed in $\mathrm{V}_{2}(8.72 \%)$.

The data presented in Table 4 clearly indicated that, the moisture content was found to be decreased during storage period irrespective of storage conditions. The lowest moisture loss was noticed in $\mathrm{S}_{3}(4.24 \%)$ whereas the highest moisture loss was observed in $\mathrm{S}_{1}(10.35 \%)$.

The data regarding the interaction effect of types of vegetable and different storage conditions reveals that, the highest moisture content was recorded by $\mathrm{V}_{3} \mathrm{~S}_{3}(90.00 \%)$ closely followed by $\mathrm{V}_{2} \mathrm{~S}_{3}(87.20 \%)$ whereas lowest content of moisture was observed in $\mathrm{V}_{1} \mathrm{~S}_{1}(80.04 \%)$ at the end of shelf life. It was found that the per cent moisture loss in primary processed leafy vegetables was ranged from $3.31 \%\left(\mathrm{~V}_{5} \mathrm{~S}_{3}\right)$ to $12.86 \%\left(\mathrm{~V}_{3} \mathrm{~S}_{1}\right)$. The moisture percentage of primary processed vegetables was found to be decreased irrespective of vegetable types and storage conditions as storage period enhanced. The lowest moisture loss in the treatment $\mathrm{V}_{5} \mathrm{~S}_{3}$ is might be due to the thick and fleshy cuticle of rajgira as compared to the remaining vegetables prevalence of low temperature and high humidity under refrigerated conditions resulted in less moisture loss. Similar results were also reported by Komolafe and Idah (2008) in okra, Kulkarni (2015) in fenugreek and spinach Patil (2016) in lettuce.

\section{Total Mineral Content (\%)}

The data with respect to effect of types of vegetable and storage conditions have been presented in Table 4. From this data it is clearly seen that, the total mineral content of primary processed leafy vegetables was significantly influenced by types of vegetables and storage conditions.

The primary processed leafy vegetables showed significant variation in the total mineral content and was found to be ranged in between $22.03 \%\left(\mathrm{~V}_{5}\right)$ to $27.57 \%\left(\mathrm{~V}_{1}\right)$. At the end of storage period, highest total mineral content was recorded in $\mathrm{V}_{3}(20.86 \%)$ followed by $\mathrm{V}_{1}(20.00 \%)$ whereas lowest total mineral content was recorded by $\mathrm{V}_{5}$ $(14.95 \%)$. Similarly, highest retention of total minerals content was observed in $\mathrm{V}_{3}(82.87$ $\%)$ and lowest was noticed in $\mathrm{V}_{5}(67.86 \%)$.

The data with respect to effect of storage conditions on the total mineral content of vegetables depicted in Table 3 . The data revealed that, the total mineral content was found to be decreased irrespective of storage conditions. The highest total mineral content and its retention was observed under $\mathrm{S}_{3}$ (20.86 \% and $86.37 \%$, respectively) followed by $S_{2}(18.79 \%$ and $77.80 \%$, respectively) and $S_{1}$ (15.11 and $62.56 \%$, respectively).

The data regarding interaction effect of types of vegetable and storage conditions on total mineral content have been presented in Table 4. It is clearly seen from the data that, the total mineral content of primary processed leafy vegetables was found to be decreased during storage period irrespective of storage conditions and types of vegetable. The highest total mineral content was recorded by $\mathrm{V}_{1} \mathrm{~S}_{3}$ $(25.23 \%)$ followed by $\mathrm{V}_{1} \mathrm{~S}_{2}(22.00 \%)$ whereas lowest total mineral content was observed in $\mathrm{V}_{5} \mathrm{~S}_{1}(12.23 \%)$ followed by $\mathrm{V}_{1} \mathrm{~S}_{1}$ $(12.77 \%)$ at the end of storage period. Similarly, the retention percentage of total mineral content was found to be maximum in $\mathrm{V}_{1} \mathrm{~S}_{3}(91.51 \%)$ followed by $\mathrm{V}_{2} \mathrm{~S}_{3}(89.52 \%)$ whereas lowest retention of total mineral content was recorded by $\mathrm{V}_{1} \mathrm{~S}_{1}(46.31 \%)$ and 
$\mathrm{V}_{5} \mathrm{~S}_{1}(55.51 \%)$. A declining trend in total mineral content of primary processed leafy vegetables was observed in all the samples during storage irrespective of types of vegetable and storage conditions. The results of present findings are in concurs with the results of Patil (2016) in minimally processed lettuce.

\section{Chemical constituent/traits}

During the present investigation of physical parameters such as moisture (\%), total mineral $(\%)$, ascorbic acid $(\mathrm{mg} / 100 \mathrm{~g})$ and total chlorophyll contents $(\mathrm{mg} / 100 \mathrm{~g})$ were estimated at initial and at termination of different treatments i.e. end of storage life. The results with respect to chemical constituents of primary processed leafy vegetables were significantly influenced by types of vegetable and storage conditions.

\section{Ascorbic acid (mg/100g)}

The data presented in Table 5 revealed that the ascorbic acid content was found to be differed significantly among the different vegetables under study. It was also noticed that, ascorbic acid content was decreased as storage period advanced in all the vegetables. Initially, among all the vegetables, $\mathrm{V}_{2}$ recorded highest amount of ascorbic acid content $(86.73 \mathrm{mg} / 100 \mathrm{~g})$ followed by $\mathrm{V}_{1}$ $(80.68 \mathrm{mg} / 100 \mathrm{~g})$ whereas lowest ascorbic acid was observed in $\mathrm{V}_{5}(40.93 \mathrm{mg} / 100 \mathrm{~g})$. At the end of storage period, highest ascorbic acid content was recorded in $\mathrm{V}_{2} \quad(62.77$ $\mathrm{mg} / 100 \mathrm{~g})$ followed by $\mathrm{V}_{1}(57.67 \mathrm{mg} / 100 \mathrm{~g})$ whereas the lowest was recorded by $\mathrm{V}_{3}(23.80$ $\mathrm{mg} / 100 \mathrm{~g})$. Similarly, the highest retention of ascorbic acid was noticed in $\mathrm{V}_{2}(72.37 \%)$ followed by $\mathrm{V}_{1}(71.47 \%)$ and lowest retention was recorded in $\mathrm{V}_{3}(47.10 \%)$ followed by $\mathrm{V}_{4}(53.75 \%)$.

It was also found that, at the end of storage life, among the storage conditions, $\mathrm{S}_{3}$ recorded highest ascorbic acid content (52.90 $\mathrm{mg} / 100 \mathrm{~g})$ followed by $\mathrm{S}_{2}(40.20 \mathrm{mg} / 100 \mathrm{~g})$ whereas lowest was noticed in $\mathrm{S}_{1}$ (26.04 $\mathrm{mg} / 100 \mathrm{~g})$. Similarly, the highest retention of ascorbic acid was recorded in $\mathrm{S}_{3}(84.31 \%)$ and lowest retention was recorded by $S_{1}$ $(41.50 \%)$. Trend of decrease in ascorbic acid content was recorded throughout the storage period irrespective of storage conditions. Similar findings were also reported by Yadav and Sehgal (1997) who stated the ascorbic acid content of fenugreek was 220.97 $\mathrm{mg} / 100 \mathrm{~g}$ and Kulkarni (2015) in fenugreek and spinach.

The data presented in Table 5 reveals that, the ascorbic acid content of primary processed leafy vegetables was significantly differed among the different vegetables irrespective of storage conditions. At the end of storage life, highest ascorbic acid was recorded in $\mathrm{V}_{2} \mathrm{~S}_{3}$ $(75.00 \mathrm{mg} / 100 \mathrm{~g})$ followed by $\mathrm{V}_{1} \mathrm{~S}_{3}(71.07$ $\mathrm{mg} / 100 \mathrm{~g})$ and lowest was recorded by $\mathrm{V}_{3} \mathrm{~S}_{1}$ $(10.63 \mathrm{mg} / 100 \mathrm{~g})$ followed by $\mathrm{V}_{4} \mathrm{~S}_{1}(11.65$ $\mathrm{mg} / 100 \mathrm{~g})$. At the end of storage life, the highest retention of ascorbic acid was recorded in $\mathrm{V}_{1} \mathrm{~S}_{3}(88.86 \%)$ followed by $\mathrm{V}_{2} \mathrm{~S}_{3}$ $(86.47 \%)$ whereas lowest was observed in $\mathrm{V}_{3} \mathrm{~S}_{1}(21.03 \%)$ followed by $\mathrm{V}_{4} \mathrm{~S}_{1}(21.24 \%)$. The decreasing trend with respect of ascorbic acid content of primary processed leafy vegetables under different storage conditions was found. This may be due to increase in storage time and respiration had played important role in ascorbic acid reduction as reported by Sharma et al. (2011) in minimally processed vegetables. The stability of ascorbic acid is generally enforced by maintaining low temperature during storage (Fennema, 1996). The loss in ascorbic acid content is attributed to both, temperature and water loss (Kader, 2002). The results of present findings are in close conformity with findings of Kulkarni (2015) in fenugreek, Patil (2016) in lettuce and Indore et al. (2017) in okra 


\section{Total chlorophyll content (mg/100 g)}

The data presented in Table 5 clearly indicated that, the total chlorophyll content of primary processed leafy vegetables was significantly influenced by the types of vegetable and storage conditions. It was found that the total chlorophyll content of primary processed leafy vegetables exhibited a decreasing trend throughout the storage period irrespective of types of vegetable and storage conditions.

It was also noticed that, the total chlorophyll content of primary processed leafy vegetables was decreased throughout the storage period irrespective of types of vegetable (Table 5). Initially, the chlorophyll content was ranged from $53.24 \mathrm{mg} / 100 \mathrm{~g}\left(\mathrm{~V}_{2}\right)$ to $90.58 \mathrm{mg} / 100 \mathrm{~g}$ $\left(\mathrm{V}_{1}\right)$. At the end of storage period, highest total chlorophyll content was recorded in $\mathrm{V}_{4}$ $(72.15 \mathrm{mg} / 100 \mathrm{~g})$ followed by $\mathrm{V}_{1}(67.64$ $\mathrm{mg} / 100 \mathrm{~g}$ ) whereas lowest was noticed in $\mathrm{V}_{2}$ $(38.91 \mathrm{mg} / 100 \mathrm{~g})$ followed by $\mathrm{V}_{3}(56.81$ $\mathrm{mg} / 100 \mathrm{~g}$ ). Further, it was also found that, highest retention of chlorophyll content was recorded in $\mathrm{V}_{5}(87.83 \%)$ and the lowest was recorded in $\mathrm{V}_{3}(68.54 \%)$ at the end of storage life.

It was noticed that, the individual effect of storage conditions on total chlorophyll content was found to be significant and showed decreasing trend during storage irrespective of storage conditions. The rate of reduction in total chlorophyll content was faster at room temperature followed by ZECC and refrigerated storage. Initially, all the storage conditions recorded total chlorophyll as $77.77 \mathrm{mg} / 100 \mathrm{~g}$ and it was found to be gradually decreased during storage. The highest total chlorophyll content was recorded in $S_{3}(70.15 \mathrm{mg} / 100 \mathrm{~g})$ whereas lowest total chlorophyll content was recorded in $\mathrm{S}_{1}(46.66$ $\mathrm{mg} / 100 \mathrm{~g}$ ) at the end of storage period. The per cent retention of total chlorophyll was highest in $S_{3}(90.20)$ and was lowest in $S_{1}$ (63.85).

Table.1 Distribution of weight into different parts of leafy vegetables and shelf life of primary processed leafy vegetables under different storage conditions

\begin{tabular}{|c|c|c|c|c|c|c|c|}
\hline \multirow[t]{2}{*}{$\begin{array}{l}\text { Sr. } \\
\text { No. }\end{array}$} & \multirow[t]{2}{*}{$\begin{array}{l}\text { Name of the } \\
\text { Vegetable }\end{array}$} & \multirow{2}{*}{$\begin{array}{c}\text { Wt. of } \\
\text { Inedible } \\
\text { Portion(g) }\end{array}$} & \multirow{2}{*}{$\begin{array}{c}\text { Wt. of } \\
\text { Edible } \\
\text { Portion } \\
\text { (g) }\end{array}$} & \multirow{2}{*}{$\begin{array}{c}\text { Edible } \\
\text { Portion } \\
(\%)\end{array}$} & \multicolumn{3}{|c|}{$\begin{array}{l}\text { Shelf life in days under } \\
\text { different storage conditions }\end{array}$} \\
\hline & & & & & RT & ZECC & RS \\
\hline 1 & Fenugreek $\left(\mathbf{V}_{1}\right)$ & 600.25 & 399.75 & 39.97 & 2 & 3 & 8 \\
\hline 2 & Coriander $\left(\mathbf{V}_{2}\right)$ & 655.80 & 344.20 & 34.40 & 2 & 3 & 6 \\
\hline 3 & Spinach $\left(\mathbf{V}_{\mathbf{3}}\right)$ & 351.50 & 648.50 & 64.80 & 2 & 4 & 8 \\
\hline 4 & Pokala $\left(V_{4}\right)$ & 609.59 & 390.41 & 39.04 & 2 & 4 & 6 \\
\hline 5 & Rajgira ( $V_{5}$ ) & 408.50 & 591.50 & 59.15 & 2 & 4 & 8 \\
\hline
\end{tabular}

RT - Room temperature

ZECC - Zero Energy Cool chamber

RS - Refrigerated storage 
Table.2 Effect types of vegetable and storage conditions on physiological loss in weight (\%) of primary processed leafy vegetables

\begin{tabular}{|c|c|c|c|c|c|c|c|c|c|c|}
\hline \multirow[t]{3}{*}{ Treatment } & \multirow{2}{*}{\multicolumn{5}{|c|}{$\begin{array}{c}\text { Physiological Loss in Weight }(\%) \\
\text { Storage period in days }\end{array}$}} & \multirow{2}{*}{\multicolumn{5}{|c|}{$\begin{array}{l}\text { Yellowing }(\%) \\
\text { Storage period in days }\end{array}$}} \\
\hline & & & & & & & & & & \\
\hline & 0 & 2 & 4 & 6 & 8 & 0 & 2 & 4 & 6 & 8 \\
\hline$V_{1} S_{1}$ & 0 & 13.11 & - & - & - & 0 & 7.14 & - & - & - \\
\hline $\mathbf{V}_{1} \mathbf{S}_{2}$ & 0 & 6.07 & 10.06 & - & - & 0 & 6.03 & 6.81 & - & - \\
\hline$V_{1} S_{3}$ & 0 & 3.45 & 5.08 & 8.00 & 11.21 & 0 & 1.01 & 2.89 & 4.89 & 5.07 \\
\hline$V_{2} S_{1}$ & 0 & 11.17 & - & - & - & 0 & 5.22 & - & - & - \\
\hline$V_{2} S_{2}$ & 0 & 7.18 & 11.48 & - & - & 0 & 3.45 & 4.95 & - & - \\
\hline$V_{2} S_{3}$ & 0 & 3.71 & 5.22 & 9.73 & - & 0 & 0.25 & 1.86 & 3.15 & - \\
\hline$V_{3} S_{1}$ & 0 & 9.19 & - & - & - & 0 & 3.91 & - & - & - \\
\hline $\mathbf{V}_{3} \mathbf{S}_{2}$ & 0 & 5.23 & 10.43 & - & - & 0 & 2.37 & 4.00 & - & - \\
\hline$V_{3} S_{3}$ & 0 & 2.90 & 4.42 & 7.91 & 9.47 & 0 & 0.44 & 0.99 & 2.67 & 3.11 \\
\hline$V_{4} S_{1}$ & 0 & 12.45 & - & - & - & 0 & 2.42 & - & - & - \\
\hline$V_{4} S_{2}$ & 0 & 5.67 & 10.01 & - & - & 0 & 1.52 & 2.73 & - & - \\
\hline$V_{4} S_{3}$ & 0 & 2.78 & 5.32 & 9.71 & - & 0 & 0.37 & 0.26 & 1.64 & - \\
\hline$V_{5} S_{1}$ & 0 & 8.32 & - & - & - & 0 & 2.50 & - & - & - \\
\hline$V_{5} S_{2}$ & 0 & 4.01 & 8.38 & - & - & 0 & 2.05 & 3.18 & - & - \\
\hline$V_{5} S_{3}$ & 0 & 2.76 & 4.58 & 7.33 & 8.25 & 0 & 0.00 & 0.34 & 1.95 & 2.03 \\
\hline $\mathrm{SE} \pm$ & & 0.0987 & 0.0339 & 0.0069 & 0.0039 & & 0.0772 & 0.0068 & 0.0042 & 0.0092 \\
\hline CD at $1 \%$ & & 0.3840 & 0.1317 & 0.0270 & 0.0153 & & 0.3002 & 0.0266 & 0.0164 & 0.0359 \\
\hline$V_{1}$ & 0 & 7.54 & 7.57 & 8.00 & 11.21 & 0 & 4.72 & 4.85 & 4.89 & 5.07 \\
\hline $\mathbf{V}_{2}$ & 0 & 7.35 & 8.35 & 9.73 & - & 0 & 2.97 & 3.03 & 3.15 & - \\
\hline $\mathbf{V}_{\mathbf{3}}$ & 0 & 5.78 & 7.43 & 7.91 & 9.47 & 0 & 2.24 & 2.49 & 2.67 & 3.11 \\
\hline$V_{4}$ & 0 & 6.97 & 7.66 & 9.71 & - & 0 & 1.43 & 1.49 & 1.64 & - \\
\hline$V_{5}$ & 0 & 5.03 & 6.48 & 7.33 & 8.25 & 0 & 1.52 & 1.76 & 1.95 & 2.03 \\
\hline $\mathrm{SE} \pm$ & & 0.0570 & 0.0196 & 0.0040 & 0.0023 & & 0.0446 & 0.0039 & 0.0024 & 0.0053 \\
\hline CD at $1 \%$ & & 0.2217 & 0.0760 & 0.0156 & 0.0089 & & 0.1700 & 0.0153 & 0.0095 & 0.0207 \\
\hline$S_{1}$ & 0 & 10.85 & - & - & - & 0 & 4.24 & - & - & - \\
\hline $\mathbf{S}_{2}$ & 0 & 5.63 & 10.07 & - & - & 0 & 3.08 & 4.18 & - & - \\
\hline $\mathbf{S}_{3}$ & 0 & 3.12 & 4.92 & 8.54 & 9.64 & 0 & 0.41 & 1.27 & 2.86 & 3.40 \\
\hline $\mathbf{S E} \pm$ & & 0.0442 & 0.0151 & 0.0031 & 0.0018 & & 0.0345 & 0.0031 & 0.0019 & 0.0041 \\
\hline CD at $1 \%$ & & 0.1717 & 0.0589 & 0.0121 & 0.0069 & & 0.1304 & 0.01 & 0.0073 & 0.0161 \\
\hline
\end{tabular}

'-' Indicates termination of treatment

$\mathbf{V}_{\mathbf{1}}$ - Fenugreek, $\quad \mathbf{V}_{\mathbf{2}}$ - Coriander, $\mathbf{V}_{\mathbf{3}}-$ Spinach, $\mathbf{V}_{\mathbf{4}}$-Pokala, $\mathbf{V}_{\mathbf{5}}$-Rajgira

$\mathbf{S}_{\mathbf{1}}$ - Room temperature, $\mathbf{S}_{\mathbf{2}}$ ZECC, $\mathbf{S}_{\mathbf{3}}$ - Refrigerated storage 
Table.3 Effect types of vegetable and storage conditions on physiological loss in weight (\%) of primary processed leafy vegetables

\begin{tabular}{|c|c|c|c|c|c|c|c|c|c|c|}
\hline \multirow[t]{3}{*}{ Treatment } & \multicolumn{5}{|c|}{ Decay (\%) } & \multicolumn{5}{|c|}{ Shriveling (\%) } \\
\hline & \multicolumn{5}{|c|}{ Storage period in days } & \multicolumn{5}{|c|}{ Storage period in days } \\
\hline & $\mathbf{0}$ & 2 & 4 & 6 & 8 & $\mathbf{0}$ & 2 & 4 & 6 & 8 \\
\hline$V_{1} S_{1}$ & 0 & 5.20 & - & - & - & 0 & 12.86 & - & - & - \\
\hline $\mathbf{V}_{1} S_{2}$ & 0 & 2.05 & 4.32 & - & - & 0 & 5.03 & 10.04 & - & - \\
\hline$V_{1} S_{3}$ & 0 & 0.90 & 1.34 & 2.93 & 3.43 & 0 & 3.03 & 5.03 & 8.15 & 11.13 \\
\hline$V_{2} S_{1}$ & 0 & 3.03 & - & - & - & 0 & 11.41 & - & - & - \\
\hline $\mathbf{V}_{2} \mathbf{S}_{2}$ & 0 & 2.72 & 3.21 & - & - & 0 & 7.79 & 10.51 & - & - \\
\hline $\mathbf{V}_{2} S_{3}$ & 0 & 1.22 & 2.03 & 2.83 & - & 0 & 5.38 & 8.00 & 10.12 & - \\
\hline $\mathbf{V}_{3} S_{1}$ & 0 & 4.01 & - & - & - & 0 & 10.57 & - & - & - \\
\hline $\mathbf{V}_{3} S_{2}$ & 0 & 2.01 & 4.10 & - & - & 0 & 6.21 & 11.05 & - & - \\
\hline$V_{3} S_{3}$ & 0 & 0.99 & 1.45 & 2.79 & 3.03 & 0 & 2.77 & 6.33 & 9.14 & 10.90 \\
\hline $\mathbf{V}_{4} \mathbf{S}_{1}$ & 0 & 3.25 & - & - & - & 0 & 11.51 & - & - & - \\
\hline $\mathbf{V}_{4} S_{2}$ & 0 & 1.63 & 3.52 & - & - & 0 & 8.25 & 14.25 & - & - \\
\hline$V_{4} S_{3}$ & 0 & 0.65 & 0.98 & 2.36 & - & 0 & 2.16 & 5.07 & 10.02 & - \\
\hline$V_{5} S_{1}$ & 0 & 3.61 & - & - & - & 0 & 14.11 & - & - & - \\
\hline$V_{5} S_{2}$ & 0 & 2.46 & 3.98 & - & - & 0 & 7.88 & 12.71 & - & - \\
\hline$V_{5} S_{3}$ & 0 & 0.90 & 0.92 & 2.57 & 2.89 & 0 & 1.96 & 4.17 & 9.47 & 9.86 \\
\hline $\mathrm{SE} \pm$ & & 0.0786 & 0.0148 & 0.0059 & 0.0042 & & 0.0366 & 0.0146 & 0.0069 & 0.00 \\
\hline CD at $1 \%$ & & 0.3057 & 0.0575 & 0.0229 & 0.0164 & & 0.1425 & 0.0566 & 0.0268 & 0.0100 \\
\hline $\mathbf{V}_{1}$ & 0 & 2.62 & 2.83 & 2.93 & 3.43 & 0 & 6.97 & 7.54 & 8.15 & 11.13 \\
\hline $\mathbf{V}_{2}$ & 0 & 2.32 & 2.62 & 2.83 & - & 0 & 8.19 & 9.26 & 10.12 & - \\
\hline $\mathbf{V}_{\mathbf{3}}$ & 0 & 2.34 & 2.72 & 2.79 & 3.03 & 0 & 6.52 & 8.69 & 9.14 & 10.90 \\
\hline $\mathbf{V}_{4}$ & 0 & 1.84 & 2.25 & 2.36 & - & 0 & 7.31 & 9.66 & 10.02 & - \\
\hline $\mathbf{V}_{5}$ & 0 & 2.44 & 2.45 & 2.57 & 2.89 & 0 & 7.98 & 8.44 & 9.47 & 9.86 \\
\hline $\mathrm{SE} \pm$ & & 0.0454 & 0.0085 & 0.0034 & 0.0024 & & 0.0212 & 0.0084 & 0.0040 & 0.0012 \\
\hline CD at $1 \%$ & & 0.1765 & 0.0332 & 0.0132 & 0.0095 & & 0.0823 & 0.0327 & 0.0155 & 0.0047 \\
\hline $\mathrm{S}_{1}$ & 0 & 3.82 & - & - & - & 0 & 12.09 & - & - & - \\
\hline $\mathbf{S}_{2}$ & 0 & 2.17 & 3.80 & - & - & 0 & 7.03 & 11.71 & - & - \\
\hline $\mathbf{S}_{3}$ & 0 & 0.94 & 1.34 & 2.70 & 3.12 & 0 & 3.06 & 5.72 & 9.38 & 11.09 \\
\hline $\mathrm{SE} \pm$ & & 0.0352 & 0.0066 & 0.0026 & 0.0019 & & 0.0164 & 0.0065 & 0.0031 & 0.0009 \\
\hline CD at $1 \%$ & & 0.1367 & 0.0257 & 0.0103 & 0.0073 & & 0.0637 & 0.0253 & 0.012 & 0.0037 \\
\hline
\end{tabular}

'-' Indicates termination of treatment

$\mathbf{V}_{1}$ - Fenugreek, $\quad \mathbf{V}_{\mathbf{2}}$ - Coriander, $\mathbf{V}_{\mathbf{3}}$ - Spinach, $\mathbf{V}_{\mathbf{4}}$-Pokala, $\mathbf{V}_{5}$-Rajgira

$\mathbf{S}_{\mathbf{1}}$ - Room temperature, $\mathbf{S}_{\mathbf{2}}$ Z ZECC, $\mathbf{S}_{\mathbf{3}}$ - Refrigerated storage 
Table.4 Effect of types of vegetable and storage conditions on moisture content of primary processed leafy vegetables

\begin{tabular}{|c|c|c|c|c|c|c|}
\hline \multirow[t]{2}{*}{ Treatment } & \multicolumn{3}{|c|}{ Moisture (\%) } & \multicolumn{3}{|c|}{ Total mineral content $(\%)$} \\
\hline & Initial & $\begin{array}{c}\text { At } \\
\text { termination }\end{array}$ & $\%$ Loss & Initial & $\begin{array}{c}\text { At } \\
\text { termination }\end{array}$ & $\begin{array}{c}\% \\
\text { Retention }\end{array}$ \\
\hline$V_{1} S_{1}$ & 90.77 & 80.04 & 10.73 & 27.57 & 12.77 & 46.31 \\
\hline $\mathbf{V}_{1} \mathbf{S}_{2}$ & 90.77 & 83.79 & 6.98 & 27.57 & 22.00 & 79.79 \\
\hline$V_{1} S_{3}$ & 90.77 & 85.80 & 4.97 & 27.57 & 25.23 & 91.51 \\
\hline $\mathbf{V}_{2} \mathbf{S}_{1}$ & 92.24 & 81.04 & 11.20 & 23.20 & 16.03 & 69.09 \\
\hline $\mathbf{V}_{2} \mathbf{S}_{2}$ & 92.24 & 82.32 & 9.92 & 23.20 & 19.23 & 82.88 \\
\hline$V_{2} S_{3}$ & 92.24 & 87.20 & 5.04 & 23.20 & 20.77 & 89.52 \\
\hline$V_{3} S_{1}$ & 94.00 & 81.14 & 12.86 & 25.17 & 20.03 & 79.57 \\
\hline$V_{3} S_{2}$ & 94.00 & 85.80 & 8.21 & 25.17 & 20.83 & 82.75 \\
\hline $\mathbf{V}_{\mathbf{3}} \mathbf{S}_{3}$ & 94.00 & 90.00 & 4.00 & 25.17 & 21.72 & 86.29 \\
\hline$V_{4} S_{1}$ & 90.17 & 80.61 & 9.55 & 22.77 & 14.47 & 63.54 \\
\hline$V_{4} S_{2}$ & 90.17 & 82.44 & 7.72 & 22.77 & 16.63 & 73.03 \\
\hline$V_{4} S_{3}$ & 90.17 & 86.28 & 3.89 & 22.77 & 19.22 & 84.40 \\
\hline$V_{5} S_{1}$ & 87.55 & 80.12 & 7.43 & 22.03 & 12.23 & 55.51 \\
\hline$V_{5} S_{2}$ & 87.55 & 82.39 & 5.16 & 22.03 & 15.27 & 69.31 \\
\hline$V_{5} S_{3}$ & 87.55 & 84.24 & 3.31 & 22.03 & 17.37 & 83.38 \\
\hline SE \pm & 0.1276 & 0.2091 & -- & 0.0298 & 0.0244 & \\
\hline CD at $1 \%$ & 0.4694 & 0.8130 & -- & 0.1159 & 0.0951 & \\
\hline$V_{1}$ & 90.77 & 83.21 & 7.56 & 27.57 & 20.00 & 72.54 \\
\hline $\mathbf{V}_{2}$ & 92.24 & 83.52 & 8.72 & 23.20 & 18.68 & 80.51 \\
\hline $\mathbf{V}_{3}$ & 94.00 & 85.65 & 8.35 & 25.17 & 20.86 & 82.87 \\
\hline$V_{4}$ & 90.17 & 83.11 & 7.06 & 22.77 & 16.77 & 73.64 \\
\hline $\mathbf{V}_{5}$ & 87.55 & 82.25 & 5.30 & 22.03 & 14.95 & 67.86 \\
\hline $\mathrm{SE} \pm$ & 0.0737 & 0.1207 & -- & 0.0172 & 0.0141 & \\
\hline CD at $1 \%$ & 0.2866 & 0.4694 & -- & 0.0669 & 0.0549 & \\
\hline $\mathbf{S}_{1}$ & 90.94 & 80.59 & 10.35 & 24.15 & 15.11 & 62.56 \\
\hline $\mathbf{S}_{2}$ & 90.94 & 83.35 & 7.59 & 24.15 & 18.79 & 77.80 \\
\hline $\mathbf{S}_{\mathbf{3}}$ & 90.94 & 86.70 & 4.24 & 24.15 & 20.86 & 86.37 \\
\hline SE \pm & 0.0571 & 0.0935 & -- & 0.0133 & 0.0109 & \\
\hline CD at $1 \%$ & 0.2220 & 0.3636 & -- & 0.0519 & 0.0425 & \\
\hline
\end{tabular}

'-' Indicates termination of treatment

$\mathbf{V}_{\mathbf{1}}$ - Fenugreek, $\quad \mathbf{V}_{\mathbf{2}}$ - Coriander, $\mathbf{V}_{\mathbf{3}}$-Spinach, $\mathbf{V}_{\mathbf{4}}$-Pokala, $\mathbf{V}_{5}$-Rajgira

$\mathbf{S}_{\mathbf{1}}$ - Room temperature, $\mathbf{S}_{\mathbf{2}}$ ZECC, $\mathbf{S}_{\mathbf{3}}$ - Refrigerated storage 
Table.5 Effect of types of vegetable and storage conditions on moisture content of primary processed leafy vegetables

\begin{tabular}{|c|c|c|c|c|c|c|}
\hline \multirow[t]{2}{*}{ Treatment } & \multicolumn{3}{|c|}{ Ascorbic acid content (mg/100g) } & \multicolumn{3}{|c|}{ Total chlorophyll content (mg/100g) } \\
\hline & Initial & $\begin{array}{c}\text { At } \\
\text { termination }\end{array}$ & $\begin{array}{c}\% \\
\text { Retention }\end{array}$ & Initial & $\begin{array}{c}\text { At } \\
\text { termination }\end{array}$ & $\begin{array}{c}\% \\
\text { Retention }\end{array}$ \\
\hline$V_{1} S_{1}$ & 80.68 & 40.91 & 50.70 & 90.58 & 55.93 & 61.74 \\
\hline $\mathbf{V}_{1} \mathbf{S}_{2}$ & 80.68 & 61.02 & 75.63 & 90.58 & 68.88 & 76.04 \\
\hline$V_{1} S_{3}$ & 80.68 & 71.07 & 88.86 & 90.58 & 78.11 & 86.23 \\
\hline$V_{2} S_{1}$ & 86.73 & 50.65 & 58.39 & 53.24 & 30.67 & 57.60 \\
\hline $\mathbf{V}_{2} \mathbf{S}_{2}$ & 86.73 & 62.66 & 72.24 & 53.24 & 41.79 & 78.49 \\
\hline$V_{2} S_{3}$ & 86.73 & 75.00 & 86.47 & 53.24 & 44.28 & 83.17 \\
\hline$V_{3} S_{1}$ & 50.53 & 10.63 & 21.03 & 83.02 & 43.31 & 52.16 \\
\hline $\mathbf{V}_{3} S_{2}$ & 50.53 & 20.25 & 40.07 & 83.02 & 55.27 & 66.57 \\
\hline $\mathbf{V}_{\mathbf{3}} \mathbf{S}_{3}$ & 50.53 & 40.51 & 80.17 & 83.02 & 71.85 & 86.54 \\
\hline$V_{4} S_{1}$ & 54.84 & 11.65 & 21.24 & 88.02 & 61.31 & 69.65 \\
\hline $\mathbf{V}_{4} \mathbf{S}_{2}$ & 54.84 & 32.81 & 59.82 & 88.02 & 72.31 & 82.15 \\
\hline$V_{4} S_{3}$ & 54.84 & 43.98 & 80.19 & 88.02 & 82.82 & 94.04 \\
\hline$V_{5} S_{1}$ & 40.93 & 16.37 & 39.99 & 73.98 & 57.10 & 77.18 \\
\hline $\mathbf{V}_{5} S_{2}$ & 40.93 & 24.25 & 59.24 & 73.98 & 64.17 & 86.73 \\
\hline$V_{5} S_{3}$ & 40.93 & 33.92 & 82.87 & 73.98 & 69.17 & 93.49 \\
\hline SE \pm & 0.4302 & 0.3344 & -- & 0.3322 & 0.3402 & \\
\hline CD at $1 \%$ & 1.6729 & 1.3006 & -- & 1.2921 & 1.3232 & \\
\hline$V_{1}$ & 80.68 & 57.67 & 71.47 & 90.58 & 67.64 & 74.67 \\
\hline $\mathbf{V}_{2}$ & 86.73 & 62.77 & 72.37 & 53.24 & 38.91 & 73.08 \\
\hline $\mathbf{V}_{3}$ & 50.53 & 23.80 & 47.10 & 83.02 & 56.81 & 68.54 \\
\hline$V_{4}$ & 54.84 & 29.48 & 53.75 & 88.02 & 72.15 & 81.97 \\
\hline$V_{5}$ & 40.93 & 24.85 & 60.71 & 73.98 & 64.98 & 87.83 \\
\hline $\mathrm{SE} \pm$ & 0.2484 & 0.1931 & -- & 0.1918 & 0.1964 & \\
\hline CD at $1 \%$ & 0.9659 & 0.7509 & -- & 0.7460 & 0.7640 & \\
\hline $\mathbf{S}_{1}$ & 62.74 & 26.04 & 41.50 & 77.77 & 49.66 & 63.85 \\
\hline $\mathbf{S}_{2}$ & 62.74 & 40.20 & 64.07 & 77.77 & 60.48 & 77.76 \\
\hline $\mathbf{S}_{\mathbf{3}}$ & 62.74 & 52.90 & 84.31 & 77.77 & 70.15 & 90.20 \\
\hline $\mathrm{SE} \pm$ & 0.1924 & 0.1496 & -- & 0.1486 & 0.1522 & \\
\hline CD at $1 \%$ & 0.7481 & 0.5817 & -- & 0.5778 & 0.5918 & \\
\hline
\end{tabular}

'-' Indicates termination of treatment

$\mathbf{V}_{\mathbf{1}}$ - Fenugreek, $\quad \mathbf{V}_{\mathbf{2}}$ - Coriander, $\mathbf{V}_{\mathbf{3}}$-Spinach, $\mathbf{V}_{\mathbf{4}}$-Pokala, $\mathbf{V}_{5}$-Rajgira

$\mathbf{S}_{\mathbf{1}}$ - Room temperature, $\mathbf{S}_{\mathbf{2}}$ ZECC, $\mathbf{S}_{\mathbf{3}}$ - Refrigerated storage 
Table.6 Effect types of vegetable and storage conditions on colour and appearance of primary processed leafy vegetables

\begin{tabular}{|c|c|c|c|c|c|c|c|c|c|c|}
\hline \multirow{2}{*}{ Treatment } & \multicolumn{4}{|c|}{ Colour } & \multicolumn{5}{c|}{ Appearance } \\
\cline { 2 - 13 } & \multicolumn{4}{|c|}{ Storage period in days } & \multicolumn{3}{c|}{ Storage period in days } \\
\cline { 2 - 12 } & $\mathbf{0}$ & $\mathbf{2}$ & $\mathbf{4}$ & $\mathbf{6}$ & $\mathbf{8}$ & $\mathbf{0}$ & $\mathbf{2}$ & $\mathbf{4}$ & $\mathbf{6}$ & $\mathbf{8}$ \\
\hline $\mathbf{V}_{\mathbf{1}} \mathbf{S}_{\mathbf{1}}$ & 9 & 5.83 & - & - & - & 9 & 8.17 & - & - & - \\
\hline $\mathbf{V}_{\mathbf{1}} \mathbf{S}_{\mathbf{2}}$ & 9 & 7.17 & 6.5 & - & - & 9 & 7.80 & 5.67 & - & - \\
\hline $\mathbf{V}_{\mathbf{1}} \mathbf{S}_{\mathbf{3}}$ & 9 & 8.00 & 8.33 & 7.42 & 6.08 & 9 & 7.50 & 7.83 & 7.42 & 6.58 \\
\hline $\mathbf{V}_{\mathbf{2}} \mathbf{S}_{\mathbf{1}}$ & 9 & 6.33 & - & - & - & 9 & 6.00 & - & - & - \\
\hline $\mathbf{V}_{\mathbf{2}} \mathbf{S}_{\mathbf{2}}$ & 9 & 6.83 & 6 & - & - & 9 & 6.83 & 6.08 & - & - \\
\hline $\mathbf{V}_{\mathbf{2}} \mathbf{S}_{\mathbf{3}}$ & 9 & 8.17 & 7.83 & 7.42 & - & 9 & 8.17 & 7.58 & 6.92 & - \\
\hline $\mathbf{V}_{\mathbf{3}} \mathbf{S}_{\mathbf{1}}$ & 9 & 7.67 & - & - & - & 9 & 7.13 & - & - & - \\
\hline $\mathbf{V}_{\mathbf{3}} \mathbf{S}_{\mathbf{2}}$ & 9 & 7.83 & 5.92 & - & - & 9 & 7.58 & 6.33 & - & - \\
\hline $\mathbf{V}_{\mathbf{3}} \mathbf{S}_{\mathbf{3}}$ & 9 & 8.33 & 7.73 & 7.67 & 6.58 & 9 & 8.17 & 8.08 & 6.33 & 6.58 \\
\hline $\mathbf{V}_{\mathbf{4}} \mathbf{S}_{\mathbf{1}}$ & 9 & 6.25 & - & - & - & 9 & 5.67 & - & - & - \\
\hline $\mathbf{V}_{\mathbf{4}} \mathbf{S}_{\mathbf{2}}$ & 9 & 6.08 & 7.17 & - & - & 9 & 6.58 & 6.83 & - & - \\
\hline $\mathbf{V}_{\mathbf{4}} \mathbf{S}_{\mathbf{3}}$ & 9 & 7.83 & 7.33 & 6.75 & - & 9 & 7.75 & 7.5 & 6.98 & - \\
\hline $\mathbf{V}_{\mathbf{5}} \mathbf{S}_{\mathbf{1}}$ & 9 & 6.25 & - & - & - & 9 & 6.25 & - & - & - \\
\hline $\mathbf{V}_{\mathbf{5}} \mathbf{S}_{\mathbf{2}}$ & 9 & 8.27 & 8.23 & - & - & 9 & 7.80 & 7.83 & - & - \\
\hline $\mathbf{V}_{\mathbf{5}} \mathbf{S}_{\mathbf{3}}$ & 9 & 8.67 & 7.80 & 7.00 & 6.75 & 9 & 8.27 & 7.92 & 7.40 & 7.15 \\
\hline
\end{tabular}

‘-' Indicates termination of treatment

$\mathbf{V}_{1}$ - Fenugreek, $\quad \mathbf{V}_{2}$ - Coriander, $\mathbf{V}_{3}-$ Spinach, $\mathbf{V}_{4}$-Pokala, $\mathbf{V}_{5}$-Rajgira

$\mathbf{S}_{\mathbf{1}}$ - Room temperature, $\mathbf{S}_{2}$ - ZECC, $\mathbf{S}_{\mathbf{3}}$ - Refrigerated storage 
Table.7 Effect types of vegetable and storage conditions on colour and appearance of primary processed leafy vegetables

\begin{tabular}{|c|c|c|c|c|c|c|c|c|c|c|}
\hline \multirow{2}{*}{ Treatment } & \multicolumn{5}{|c|}{ Aroma } & \multicolumn{5}{c|}{ Overall acceptability } \\
\cline { 2 - 13 } & \multicolumn{4}{|c|}{ Storage period in days } & \multicolumn{5}{c|}{ Storage period in days } \\
\hline & $\mathbf{0}$ & $\mathbf{2}$ & $\mathbf{4}$ & $\mathbf{6}$ & $\mathbf{8}$ & $\mathbf{0}$ & $\mathbf{2}$ & $\mathbf{4}$ & $\mathbf{6}$ & $\mathbf{8}$ \\
\hline $\mathbf{V}_{\mathbf{1}} \mathbf{S}_{\mathbf{1}}$ & 9 & 5.00 & - & - & - & 9 & 5.50 & - & - & - \\
\hline $\mathbf{V}_{\mathbf{1}} \mathbf{S}_{\mathbf{2}}$ & 9 & 6.33 & 6.67 & - & - & 9 & 6.75 & 5.23 & - & - \\
\hline $\mathbf{V}_{\mathbf{1}} \mathbf{S}_{\mathbf{3}}$ & 9 & 7.67 & 8.00 & 7.08 & 6.33 & 9 & 7.88 & 7.86 & 7.13 & 6.33 \\
\hline $\mathbf{V}_{\mathbf{2}} \mathbf{S}_{\mathbf{1}}$ & 9 & 6.83 & - & - & - & 9 & 6.17 & - & - & - \\
\hline $\mathbf{V}_{\mathbf{2}} \mathbf{S}_{\mathbf{2}}$ & 9 & 7.17 & 7.17 & - & - & 9 & 6.96 & 6.27 & - & - \\
\hline $\mathbf{V}_{\mathbf{2}} \mathbf{S}_{\mathbf{3}}$ & 9 & 7.67 & 7.67 & 7.17 & - & 9 & 8.04 & 7.64 & 7.04 & - \\
\hline $\mathbf{V}_{\mathbf{3}} \mathbf{S}_{\mathbf{1}}$ & 9 & 6.17 & - & - & - & 9 & 7.03 & - & - & - \\
\hline $\mathbf{V}_{\mathbf{3}} \mathbf{S}_{\mathbf{2}}$ & 9 & 6.25 & 5.98 & - & - & 9 & 7.24 & 6.12 & - & - \\
\hline $\mathbf{V}_{\mathbf{3}} \mathbf{S}_{\mathbf{3}}$ & 9 & 7.83 & 7.50 & 6.83 & 6.17 & 9 & 8.14 & 7.78 & 6.95 & 6.37 \\
\hline $\mathbf{V}_{\mathbf{4}} \mathbf{S}_{\mathbf{1}}$ & 9 & 6.83 & - & - & - & 9 & 6.39 & - & - & - \\
\hline $\mathbf{V}_{\mathbf{4}} \mathbf{S}_{\mathbf{2}}$ & 9 & 6.67 & 6.17 & - & - & 9 & 6.87 & 6.62 & - & - \\
\hline $\mathbf{V}_{\mathbf{4}} \mathbf{S}_{\mathbf{3}}$ & 9 & 7.58 & 7.00 & 6.08 & - & 9 & 7.56 & 7.43 & 6.51 & - \\
\hline $\mathbf{V}_{\mathbf{5}} \mathbf{S}_{\mathbf{1}}$ & 9 & 6.25 & - & - & - & 9 & 6.25 & - & - & - \\
\hline $\mathbf{V}_{\mathbf{5}} \mathbf{S}_{\mathbf{2}}$ & 9 & 7.88 & 7.50 & - & - & 9 & 8.01 & 7.78 & - & - \\
\hline $\mathbf{V}_{\mathbf{5}} \mathbf{S}_{\mathbf{3}}$ & 9 & 8.17 & 7.58 & 6.75 & 6.35 & 9 & 8.35 & 7.96 & 7.33 & 6.74 \\
\hline & - & & & & & \\
\hline
\end{tabular}

'-' Indicates termination of treatment

$\mathbf{V}_{\mathbf{1}}$ - Fenugreek, $\quad \mathbf{V}_{\mathbf{2}}$ - Coriander, $\mathbf{V}_{\mathbf{3}}-$ Spinach, $\mathbf{V}_{\mathbf{4}}$-Pokala, $\mathbf{V}_{5}$-Rajgira

$\mathbf{S}_{\mathbf{1}}$ - Room temperature, $\mathbf{S}_{\mathbf{2}}$ ZECC, $\mathbf{S}_{\mathbf{3}}$ - Refrigerated storage 
Table.8 Effect of types of vegetable and storage conditions on total microbial count (log cfu/g) of primary processed leafy vegetables

\begin{tabular}{|c|c|c|}
\hline \multirow[t]{2}{*}{ Treatment } & \multicolumn{2}{|c|}{ Total Microbial Count (log cfu/g) } \\
\hline & Initial & At termination \\
\hline$V_{1} S_{1}$ & 7.55 & 7.68 \\
\hline$V_{1} S_{2}$ & 7.55 & 7.60 \\
\hline $\mathbf{V}_{1} S_{3}$ & 7.55 & 7.47 \\
\hline$V_{2} S_{1}$ & 7.45 & 7.55 \\
\hline$V_{2} S_{2}$ & 7.45 & 7.49 \\
\hline$V_{2} S_{3}$ & 7.45 & 7.41 \\
\hline $\mathbf{V}_{3} S_{1}$ & 7.35 & 7.55 \\
\hline $\mathbf{V}_{3} S_{2}$ & 7.35 & 7.46 \\
\hline$V_{3} S_{3}$ & 7.35 & 7.36 \\
\hline$V_{4} S_{1}$ & 7.28 & 7.62 \\
\hline$V_{4} S_{2}$ & 7.28 & 7.49 \\
\hline$V_{4} S_{3}$ & 7.28 & 7.42 \\
\hline$V_{5} S_{1}$ & 6.76 & 7.35 \\
\hline$V_{5} S_{2}$ & 6.76 & 7.13 \\
\hline $\mathbf{V}_{\mathbf{5}} \mathbf{S}_{\mathbf{3}}$ & 6.76 & 7.01 \\
\hline $\mathrm{SE} \pm 1 \%$ & 0.0165 & 0.0031 \\
\hline CD at $1 \%$ & 0.0640 & 0.0121 \\
\hline$V_{1}$ & 7.55 & 7.58 \\
\hline $\mathbf{V}_{2}$ & 7.45 & 7.48 \\
\hline $\mathbf{V}_{3}$ & 7.35 & 7.45 \\
\hline $\mathbf{V}_{4}$ & 7.28 & 7.51 \\
\hline $\mathbf{V}_{5}$ & 6.76 & 7.24 \\
\hline $\mathrm{SE} \pm 1 \%$ & 0.0095 & 0.0018 \\
\hline CD at $1 \%$ & 0.0370 & 0.0070 \\
\hline $\mathbf{S}_{1}$ & 7.29 & 7.66 \\
\hline $\mathbf{S}_{2}$ & 7.29 & 7.57 \\
\hline $\mathbf{S}_{3}$ & 7.29 & 7.47 \\
\hline $\mathrm{SE} \pm 1 \%$ & 0.0074 & 0.0014 \\
\hline CD at1\% & 0.0286 & 0.0054 \\
\hline
\end{tabular}

'-' Indicates termination of treatment

$\mathbf{V}_{\mathbf{1}}$ - Fenugreek, $\quad \mathbf{V}_{\mathbf{2}}$ - Coriander, $\mathbf{V}_{\mathbf{3}}$ - Spinach, $\mathbf{V}_{\mathbf{4}}$-Pokala, $\mathbf{V}_{5}$-Rajgira

$\mathbf{S}_{\mathbf{1}}$ - Room temperature, $\mathbf{S}_{\mathbf{2}}$ Z ZECC, $\mathbf{S}_{\mathbf{3}}$ - Refrigerated storage 
Fig.1 Appearance life of primary processed leafy vegetables under different storage conditions

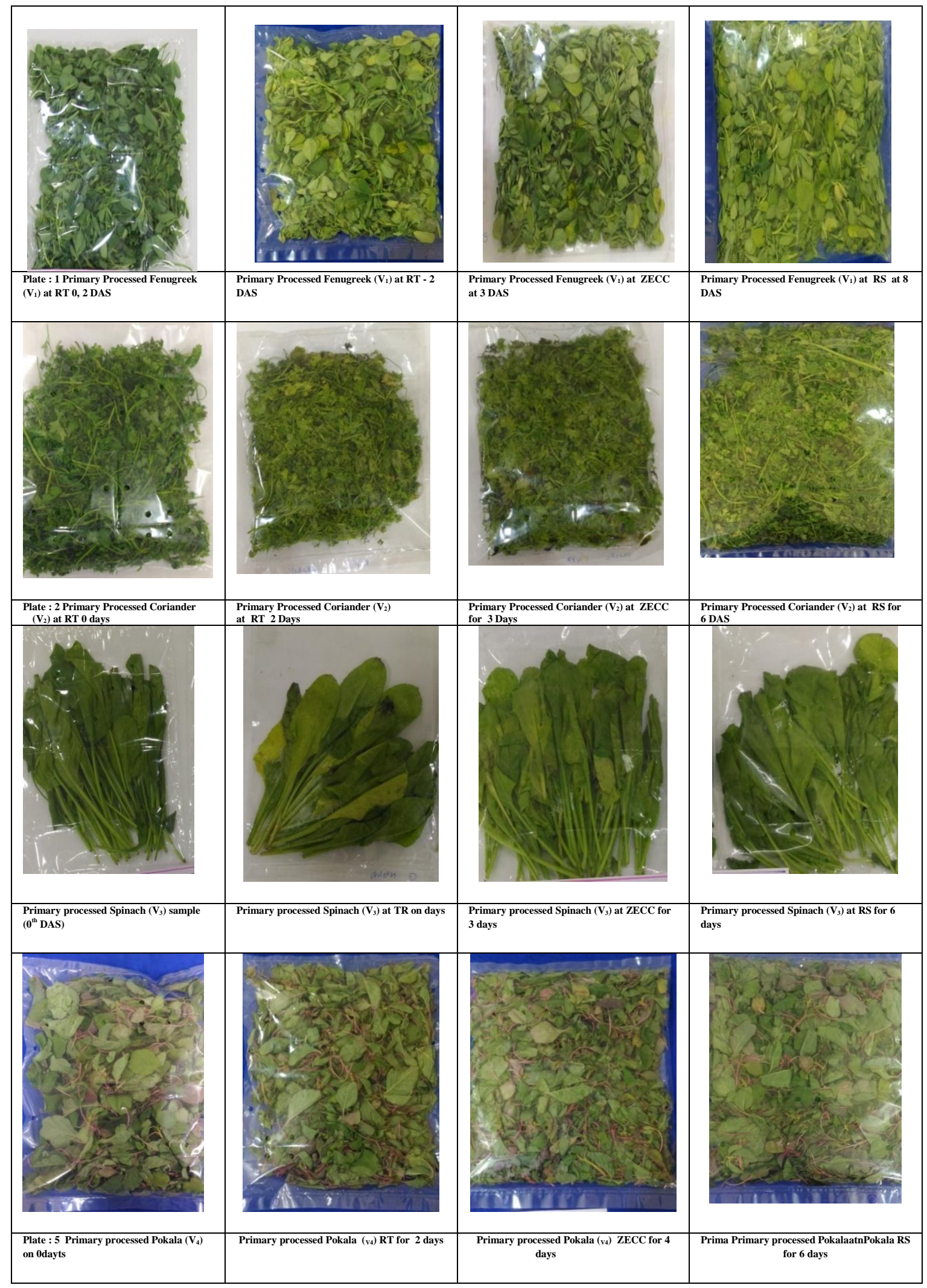




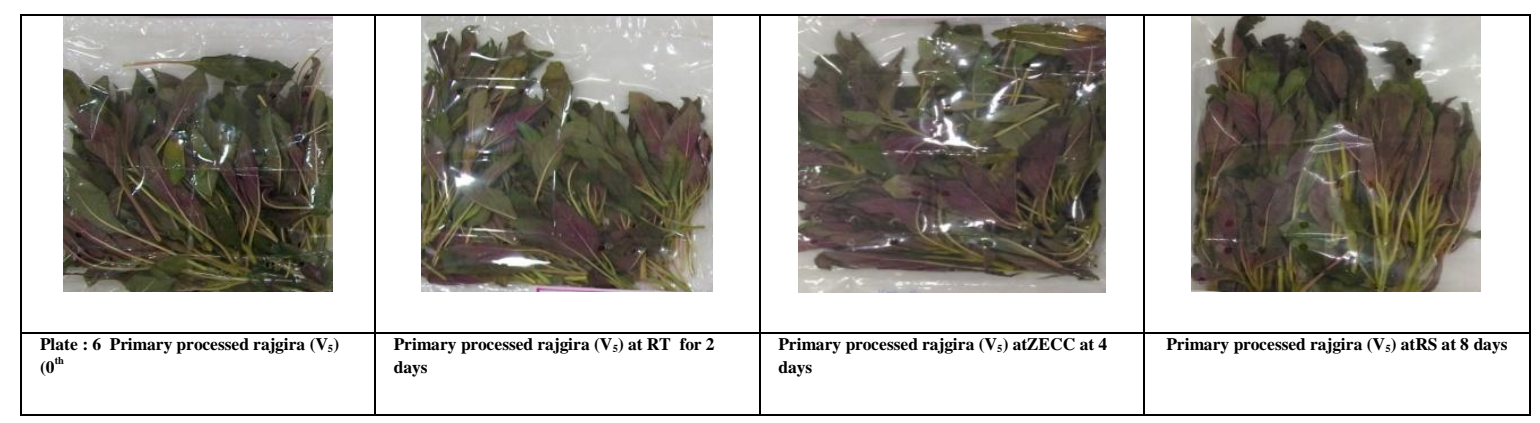

From the data presented in Table 5, it is clearly seen that, the total chlorophyll content was significantly influenced by the types of vegetable and storage conditions. At the end of storage period, $\mathrm{V}_{4} \mathrm{~S}_{3}$ recorded highest total chlorophyll content $(82.82 \mathrm{mg} / 100 \mathrm{~g})$ followed by $\mathrm{V}_{1} \mathrm{~S}_{3}(78.11 \mathrm{mg} / 100 \mathrm{~g})$ whereas lowest was found in $\mathrm{V}_{2} \mathrm{~S}_{1}(30.67 \mathrm{mg} / 100 \mathrm{~g})$ followed by $\mathrm{V}_{2} \mathrm{~S}_{2}(41.79 \mathrm{mg} / 100 \mathrm{~g})$. The per cent retention of total chlorophyll content was found to be highest in $\mathrm{V}_{4} \mathrm{~S}_{3}(94.04 \%)$ followed by $\mathrm{V}_{5} \mathrm{~S}_{3}(93.49 \%)$ whereas lowest retention was recorded in $\mathrm{V}_{3} \mathrm{~S}_{1}(52.16 \%)$ followed by $\mathrm{V}_{1} \mathrm{~S}_{1}(61.74 \%)$. All the treatments at refrigerated storage conditions showed better retention of chlorophyll content. The low oxygen and high carbon dioxide concentration can prevent chlorophyll degradation. Presence of vents has failed to increase carbon dioxide concentration, thus leading to higher amount of degradation of chlorophyll. The principle causes of the breakdown of chlorophyll are $\mathrm{pH}$ changes mainly due to leakage of organic acids from the vacuole, oxidative system and chlorophyllases (Wills et al., 1989). The decreasing trend of chlorophyll content with advancement of storage has been reported Abe and Watada (1991) and Rai et al. (2009) in shredded cabbage. The results of present findings are in close conformity with findings of Kulkarni (2015) who reported that, the total chlorophyll content in fenugreek and spinach was found to be decreased with increase in temperature and decrease in humidity.

\section{Sensorial evaluation of primary processed leafy vegetables}

\section{Colour}

The data presented in Table 6 clearly indicated that, the sensorial score for colour of primary processed leafy vegetables was found to be decreased during the storage period irrespective of storage conditions and types of vegetable. The highest score for colour was recorded by $\mathrm{V}_{5} \mathrm{~S}_{3}$ (8.67) whereas lowest score for colour was recorded in $\mathrm{V}_{1} \mathrm{~S}_{1}$ (5.83) closely followed by $\mathrm{V}_{4} \mathrm{~S}_{2}$ (6.08) and $\mathrm{V}_{5} \mathrm{~S}_{1}(6.25)$ at the end of $2^{\text {nd }}$ day of storage. On $6^{\text {th }}$ day of storage treatment combination $\mathrm{V}_{3} \mathrm{~S}_{3}$ recorded highest score (7.67) whereas lowest score for colour was recorded in $\mathrm{V}_{4} \mathrm{~S}_{3}$ (7.00).

On $8^{\text {th }}$ day of storage, $\mathrm{V}_{5} \mathrm{~S}_{3}$ recorded highest score (6.75) while $\mathrm{V}_{1} \mathrm{~S}_{3}$ recorded lowest score (6.08) for colour. Similar results were reported by Sharangi et al., (2015) in coriander, Patil (2016) in lettuce and Indore et al. (2017) in okra who stated that the vegetables having good total chlorophyll content had recorded higher score for colour. Storage conditions were played vital role in getting score for colour. The change in colour of leaves adversely affects the quality and market acceptance which is more under ambient storage and packaging material used. The decreasing trend was found in colour throughout the storage period irrespective of types of vegetables and storage conditions. 


\section{Appearance}

The data with respect to effect of types of vegetable and storage conditions on sensorial score for appearance of primary processed leafy vegetables have been presented in Table 6 . The data revealed that, highest score for appearance was recorded by the treatment combination of $\mathrm{V}_{5} \mathrm{~S}_{3}$ (8.27) whereas lowest score was recorded in $\mathrm{V}_{4} \mathrm{~S}_{1}(5.67)$ on $2^{\text {nd }}$ day of storage. On $6^{\text {th }}$ day of storage, the score for appearance was ranged in between 6.33 $\left(\mathrm{V}_{3} \mathrm{~S}_{3}\right)$ to $7.42\left(\mathrm{~V}_{1} \mathrm{~S}_{3}\right)$. The results of present findings are in concurs with earlier research work reported by Narang et al. (2016) in fenugreek and Patil (2016) in lettuce.

\section{Aroma}

The data with respect to interaction of types of vegetable and storage conditions on sensorial score for aroma have been depicted in Table 7. The storage conditions showed marked effect on aroma of the samples used for investigation. On $2^{\text {nd }}$ day of storage, $\mathrm{V}_{5} \mathrm{~S}_{3}$ (8.17) recorded highest score for aroma followed by treatment $\mathrm{V}_{5} \mathrm{~S}_{2}$ (7.88) and lowest score was recorded by $\mathrm{V}_{1} \mathrm{~S}_{1}$ (5.00) followed by $V_{3} S_{1}(6.17)$. On $6^{\text {th }}$ day of storage, highest score for aroma was noticed in $\mathrm{V}_{2} \mathrm{~S}_{3}$ (7.17) closely followed by $\mathrm{V}_{1} \mathrm{~S}_{3}$ (7.08) whereas lowest score for aroma was recorded by $\mathrm{V}_{4} \mathrm{~S}_{3}$ (6.08). At the end of $8^{\text {th }}$ day of storage, $\mathrm{V}_{5} \mathrm{~S}_{3}$ recorded highest score of 6.35 and lowest score was recorded by $\mathrm{V}_{3} \mathrm{~S}_{3}$ (6.17). In all the treatments, decreasing trend with respect to score for aroma was found throughout the storage period. At $\mathrm{S}_{1}$ storage conditions, aroma was fading out more rapidly than $S_{2}$ and $S_{3}$. The $S_{3}$ storage conditions had highest score for aroma and more marketable acceptability than $S_{1}$ and $S_{2}$ conditions. The $S_{3}$ conditions had highest humidity and lowest temperature which preserves aroma of vegetables for longer. The similar results were recorded by Brar et al. (2013) in fenugreek who stated that perforations did not allowed the accumulation of $\mathrm{O}_{2}$ and $\mathrm{CO}_{2}$ and resulted into better retention of aroma.

\section{Overall acceptability}

Overall acceptability of primary processed leafy vegetables was recorded according to the score gained by the other sensorial characters which were used to evaluate colour, appearance, texture, aroma recorded and presented in Table 7. It was noticed that, as storage period advanced overall acceptability of vegetables decreased irrespective of types of vegetables and storage conditions. The data revealed that the treatment combination of $\mathrm{V}_{5} \mathrm{~S}_{3}$ recorded highest score for overall acceptability (8.35) followed by $\mathrm{V}_{3} \mathrm{~S}_{3}(8.14)$ whereas lowest score was recorded by $\mathrm{V}_{1} \mathrm{~S}_{1}(5.50)$ followed by $\mathrm{V}_{2} \mathrm{~S}_{1}(6.17)$ on $2^{\text {nd }}$ day of storage. On $6^{\text {th }}$ day of storage, $\mathrm{V}_{5} \mathrm{~S}_{3}$ recorded highest score (7.33) and lowest score was recorded by $\mathrm{V}_{4} \mathrm{~S}_{3}(6.51)$. Similar trend was found on $8^{\text {th }}$ day of storage where highest score for overall acceptability was recorded by $\mathrm{V}_{5} \mathrm{~S}_{3}(6.74)$ followed by $\mathrm{V}_{3} \mathrm{~S}_{3}$ (6.37) and $\mathrm{V}_{1} \mathrm{~S}_{3}$ (6.33) as the samples were stored under $\mathrm{S}_{3}$ conditions.

Further, it was found that refrigerated storage was found to be effective in maintaining the colour, appearance, texture, aroma throughout the storage period and maximum overall acceptability might be due to low temperature during storage which led to reduced minimum moisture and physiological loss in weight. The results of present findings are in accordance with results reported by Kim et al. (2004) in salad savoy, Jha and Matsuoka, (2005) in tomato and Indore et al. (2017) in okra.

\section{Shelf life}

The primary processed leafy vegetables packed in 200-gauge polyethylene bags with $2 \%$ vents were stored at different storage conditions and recorded the variation in the 
shelf-life primary processed leafy vegetables under different storage condition as depicted in Table 1.

From the data represented in Table 1, it is clearly seen that, all the vegetables under study could be stored up to 2 days at RT. It was also found that fenugreek and coriander recorded shelf life of 3 days while spinach, pokala and rajgira recorded the shelf life up to 4 days when stored at zero energy cool chamber. The variation in shelf-life of primary processed vegetables stored at $S_{1}$ and $\mathrm{S}_{2}$ may be due to lower temperature and higher humidity could be maintained in zero energy cool chamber than room temperature.

In general, all the samples of primary processed leafy vegetables stored at zero energy cool chamber were found to be fresh, attractive and have good consumer's acceptance at the end of shelf life than the samples stored at room temperature as reported by Garande (1992) in jamun fruits. Rayaguru et al. (2010) recorded that the shelf life of potato, tomato, brinjal, mango, banana and spinach could be extended up to 3-15 days in zero energy cool chamber than room temperature and this extended shelf life may be due to the cool chamber where average temperature of its environment can be lowered by less by $5-8{ }^{0} \mathrm{C}$ than the outside and maintained more than $90 \% \mathrm{RH}$.

The highest shelf life of 8 days was recorded by fenugreek, spinach and rajgira while 6 days of shelf life was recorded by coriander and pokala when stored at refrigerated storage. This might be due to the steady maintained lower temperature and higher humidity than $S_{1}$ and $S_{2}$ conditions. The results of present findings are in concurs with the findings of Jaggi et al. (2005) in spinach and fenugreek, Patil (2016) in lettuce and Indore et al. (2017) in okra.

\section{Total microbial count $(\log \mathrm{cfu} / \mathrm{g})$}

The data presented in Table 8 clearly indicated that, storage conditions had significant effect on total microbial count in present investigation. Initially, $\mathrm{V}_{1}, \mathrm{~V}_{2}, \mathrm{~V}_{3}, \mathrm{~V}_{4}$ and $V_{5}$ recorded $7.55,7.45,7.35,7.28$ and $6.76 \mathrm{log} \mathrm{cfu} / \mathrm{g}$ of total microbial count, respectively. At the end of storage period, $\mathrm{V}_{1}$ recorded highest microbial count (7.58 log cfu $/ g)$ followed by $\mathrm{V}_{4}(7.51 \log \mathrm{cfu} / \mathrm{g})$ and lowest was recorded in V5 (7.24log cfu /g). Increasing trend in total microbial count was observed in all the vegetables irrespective of storage conditions.

Individual storage conditions had significant effect on total microbial count (Table 8). At the end of storage period, $S_{1}$ storage conditions showed highest microbial count (7.66 log cfu/g) followed by $\mathrm{S}_{2}, \mathrm{~S}_{3}$ whereas the $\mathrm{S}_{3}$ storage conditions recorded lowest microbial count $(7.47 \log \mathrm{cfu} / \mathrm{g})$. This might be due to low temperature and high humidity which restrict the growth of microbes and recorded lowest total microbial count.

Interaction of types of vegetables and storage conditions had significant effect on total microbial count as depicted in Table 8. The data revealed that increasing trend was noticed in total microbial count throughout the storage irrespective of types of vegetable and storage conditions. At the end of storage life, highest total microbial count was recorded $\mathrm{V}_{1} \mathrm{~S}_{1}$ (7.68 $\mathrm{log} \mathrm{cfu} / \mathrm{g}$ ) followed by $\mathrm{V}_{1} \mathrm{~S}_{2}$ (7.60) whereas lowest microbial count was recorded in $\mathrm{V}_{5} \mathrm{~S}_{3}$ and $\mathrm{V}_{5} \mathrm{~S}_{2}$ as 7.01log cfu $/ \mathrm{g}$ and 7.13log cfu /g, respectively. It was also found that microbial growth was limited at refrigerated storage $\left(5 \pm 1^{\circ} \mathrm{C}\right)$ where low temperature during storage reduced respiration rate, senescence and retarded growth of spoilage micro-organisms while ZECC storage facilitated its proliferation. Patil (2016) recorded the least microbial count on lettuce at the end of 15 days of 
storage. The results of present findings are in conformity with the findings reported by Froder, et al. (2007) in vegetable salad and Zenoozian (2011) in leafy vegetables and Patil (2016) in lettuce.

In conclusion, the primary processed rajgira packed in 200-gauge polyethylene bag with $2 \%$ vents and stored at refrigerated storage $\left(5 \pm 1^{\circ} \mathrm{C}\right)$, effectively restricted microbial growth maintained physico-chemical attributes with minimum physiological loss in weight and \% moisture loss resulted in enhanced appearance, texture with highest overall acceptability. Among the all leafy vegetables, the rajgira showed lesser loss in physico-chemical parameters than other remaining vegetables irrespective of storage conditions. Among the three storage conditions refrigerated storage $\left(5 \pm 1^{\circ} \mathrm{C}\right)$ was found to be the best storage condition for better retention of physico-chemical qualities of different leafy vegetables as compared to zero energy cool chamber and room temperature. The shelf life of fenugreek, spinach and rajgira was extended up to 8 days whereas coriander and pokala recorded 6 days shelf life when stored under refrigerated storage $\left(5 \pm 1^{\circ} \mathrm{C}\right)$.

\section{References}

Abe, K. and A. E. Watada.1991. Ethylene absorbent to maintain quality of lightly processed fruits and vegetables. J. Food Sci., 56: 1589-1592.

AOAC. 2010. International Official Methods of Analysis, $18^{\text {th }}$ Edn., Association of Official Analytical Chemists, Washington DC, USA.

Ambuko, J., F. Wanjiru, C. G. Nhemining, W. O. Owinoand and E. Mwachoni. 2017. Preservation of post-harvest quality of leafy amaranth (Amaranthus spp.) vegetable using evaporating cooling. Journal of Food Quality. pp:1-6, Article ID

5303156, https://doi.org/10.1155/2017/5303156.

Amerine, M. A., R. M. Pangborn and E. B. Roessler. 1965. Laboratory studies: Quantity-Quality Evaluation in Principles of Sensory Evaluation of Foods Academic Press, New York. pp. 349-397.

Ben-Yehoshua, S.1987. Transpiration water stress and gas exchange. In: Post-harvest Physiology of Vegetables, Eds. J. Weichmann, Marcel Dekker, Inc., New York. pp. 113-170.

Borah, S., A. M. Baruah, A. K. Das and J. Borah. 2008. Determination of mineral content in commonly grown green leafy vegetables. Postharvest Biol. and Technol., 28: 226-229.

Brar. J., K. D. Rai, R. Singh and N. Kaur. 2013. Biochemical and physiological changes in Fenugreek (Trigonella foenum - graecum L.) leaves during storage under modified atmosphere packaging. J. Food Sci. Technol., 50(4): 696- 704.

Brown, S. K. and M. C. Bourne. 2002. Assessment of components of fruit firmness in selected sweet cherry genotypes. Hort. Science, 23: 902-904.

Chauhan, D. V. S. 1981. Vegetable Production in India, pp: 60-69.

Devadas, R. P. and S. Soroja. 1980. Availability of iron and $\beta$ - carotenoid from amaranth to children. Proceedings of II ${ }^{\text {nd }}$ Amarath Conference. Emmaus PA, Rodale Press, pp: $15-21$.

Fennema, R. O. 1996. Food Chemistry, $3^{\text {rd }}$ Edition. Marcel Dekker, Inc. New York.

Froder, H., G. C. Martins, L. K. Oliveira, M. Landgraf, D. G. Bernadette, M. Franco and M. Destro. 2007. Minimally processed vegetable salads: Microbial quality evaluation. Journal of Food Protection, 70(5): 1277- 1280.

Garande, V.K. 1992. Studies on maturity indices, storage and processing of jamun. (Syzygium cuminii Skeels) fruits. M.Sc. (Agri.) thesis submitted to Dr. BSKKV, Dapoli, (M. S.).

Gibson, R. S.1994. Zinc nutrition in developing countries. Nutr. Res., 7: $151-173$.

Gihan, G. A. 2010. Effect of gamma radiation 
on microbial load and chemical constituents of banana fruits stored under different temperatures. Res. J. Agril. Biol. Sci.,6(4): 431-442.

Gomez, S., S. K. Roy and R. K. Pal. 2003. Primary processing of fenugreek (Trigonellafoenumgraecum) - An ecofriendly approach for convenience and quality.Plant Foods for Human Nutrition, $58: 1-10$.

Gopalan, C., B. V. Ramasatri and S.C. Balasubramanian. 1982. Nutritive Value of Indian Foods, ICAR, New Delhi, pp: 64-72.

Hou, J., Li. Z. Hua, Mo. W. Gui and Qu. S. Hai. 2003. Study on cold storage effect of film packaging of spinach. Food Science and Technology. pp. 5.

Indore, H. D., V. K. Garande, S. S. Dhumal, D. R. Patgaonkar, V. S. Patil, P. N. Sonawane. 2017. Effect of packaging materials and storage conditions on the shelf life and quality of okra. International Journal of Advanced Research, 4(11): 257-265.

Jaggi, M. P., R. Sharma and V. Sahiba. 2005. Acceptability of spinach (Spinacea oleracea) and fenugreek (Trigonellafoenumgraecum L.) stored in flexible consumer packets. J. Dairying and Home Sci., 24(2):137-141.

Jha, S. N. and T. Matsuoka. 2005. Determination of post-harvest storage life of tomato fruits. J. Food Sci. Technology,42(6):526-529.

Kader, A. A. 2002. Postharvest Technology of Horticultural Crops, third edition. University of California, Agriculture and Natural Resources, Publication No. 3311. pp: 535.

Kakade, A., P. More, S. Jadhav and V. Bhosale. 2015. Shelf life extension of fresh - cut spinach. International Journal of Agriculture, Environment and Biotechnology, 8(3): 609-614.

Kaur, C. and H. C. Kapoor. 2000. Minimal processing of fruits and vegetable. Indian FoodPacker, 156 - 164.

Kim, J. G., Y. Luo and K. C. Gross. 2004.
Effect of package film on the quality of fresh cut salad savoy. Post-harvest Biology and Technol., 32:99-107.

Komolafe, G. O. and P. A. Idah. 2008. Effect of temperature and time on moisture content, texture and texture of okra. Nig. Food $J ., 26(2): 106-113$.

Kulkarni, P. S. 2015. Studies on packaging and storage of spinach and fenugreek. M.Sc. (Agri.) thesis submitted to MPKV, Rahuri, (M. S.).

Narang, R., R. Sharma and M. S. Alam. 2016. Shelf - life enhancement of fresh Fenugreek (Trigonellafoenum - graecum) under refrigerated condition. Intl. J. Food Ferment. Technol., 6(2): 443- 449.

Negi, P. S. and S. K. Roy. 2004. Changes in beta carotene and ascorbic acid contents of fresh amaranth and fenugreek leaves during storage by low cost technique. Plant Foods for Human Nutrition, 58(3): 225-230.

Panse, V. G. and P. V. Sukhatme. 1985. Statistical Methods of Agricultural Workers, ICAR, New Delhi. pp. 143-147.

Patil, S. 2016. Evaluation of lettuce cultivars and their forms for postharvest behavior during storage. M. Sc. (Hort.) thesis submitted to MPKV, Rahuri, (M. S.).

Prakash, D. and M. Pal. 1991. Nutritional and anti-nutritional composition of vegetable and grain amaranth leaves, J. Sci. Food Agri., 57 (4): 573 - 585.

Qadri, O. S., B. Yousuf and A. K. Shrivastava. 2015. Fresh - Cut fruits and vegetables Critical factors influencing microbiology and novel approaches to prevent microbial risks $-A$ review. Food and Agriculture, 1: 1-11.

Rai, D. R., K. Narsaiah, D. K. Bharati, P. M. K. Reddy and S. S. Brar. 2009. Modified atmosphere packaging of minimal processing and storage of shredded cabbage. J. Food Sci. Technol., 46(5):436-439.

Ranganna, S. 2005. Hand Book of Analysis and Quality Control for Fruit and Vegetable Products. New Delhi: Tata McGraw-Hill Publishing Co. Ltd., $12^{\text {th }}$ reprint. $2^{\text {nd }}$ 
edition. 1-1112.

Rayaguru, K., Md. K. Khan and N. R. Sahoo. 2010. Water use optimization in zero energy cool chambers for short term storage of fruits and vegetables in coastal area. J. Food Sci. Technol.,47(4): 437441.

Reddy J. B., P. Bharati, K. Ramachandra, B. V. Naik, I. Sunanda and S. Hasalkar. 2013. Effect of packaging materials on shelf life of minimally processed rajagira leaves (Amaranthus paniculatus L.). Karnataka J. Agric. Sci., 26(2): 285-287.

Sharma, M., S. Lakshman, S. Ferguson, D.T. Ingram, Y. Luo and J. Patel. 2011. Effect of modified atmosphere packaging on the persistence and expression of virulence factors of Escherichia coli 0157: $\mathrm{H7}$ on shredded iceberg lettuce. J. Food Prot., 74(5): 718-726.

Sharangi, B. A., S. Guha and I. Chakrabarty. 2015. Effect of different packaging materials on storage life of fresh coriander (Coriandrum sativum $\mathrm{L}$ ) leaves. Nature and Science; 13(6):100-108.

Thompson, J. F. 2004. Pre-cooling and Storage facilities. Washington: United States Dept. of Agriculture-USDA. Agric. Handbook. No. 66.
Waskar, D. P., B. B. Yadav and V. K. Garande. 1999. Influence of various packaging materials on storage behaviour of bottle gourd under different storage conditions. Indian J. Agric. Res., 33(4):287-292.

Watada, A. E. and S. D. Kim. 1987. Quality of green beans, bell peppers and spinach stored in polythene bags. J. Food Sci.,52(6): 1637 - 1641.

Wills, R. B. H., W. B. Mcglasson, D. Graham, T.H. Lee and E.G. Hall. 1989. Postharvest: An introduction to the physiology and handling of fruits and vegetables. South China Printing Company Limited, 3rd edn., pp: 170-190.

Yadav, S. K. and S. Sehgal. 1997. Effect of home processing and storage on ascorbic acid and carotene content of Bathua (Chenopodium album) and fenugreek (Trigonella foenumgraecum) leaves. Plant Foods for HumanNutrition,50: 239247.

Zenoozian, M. S. 2011. Combined effect of packaging method and temperature on the leafy vegetables properties. Int. J. Environ. Sci. Development, 2(2): 124-12.

\section{How to cite this article:}

Garande, V.K., P.D. Raut, U.S. Shinde, S.S. Dhumal, P.N. Sonawane and S.A. Sarvade. 2019. Studies on Storage Behavior of Primary Processed Leafy Vegetables under Different Storage Conditions. Int.J.Curr.Microbiol.App.Sci. 8(06): 2249-2272. doi: https://doi.org/10.20546/ijcmas.2019.806.268 